Florida International University FIU Digital Commons

1991

\title{
A study of the characteristics of successful small black-owned enterprises in Dade County, Florida
}

Granville Alfonso Dickson

Florida International University

DOI: $10.25148 /$ etd.FI14062286

Follow this and additional works at: https://digitalcommons.fiu.edu/etd

Part of the Education Commons

\section{Recommended Citation}

Dickson, Granville Alfonso, "A study of the characteristics of successful small black-owned enterprises in Dade County, Florida" (1991). FIU Electronic Theses and Dissertations. 2814.

https://digitalcommons.fiu.edu/etd/2814 
ABSTRACT OF THE DISSERTATION

A Study of the Characteristics of Successful Small Black-owned Enterprises in Dade County,

Florida

by

Granville Alfonso Dickson

Florida International University, 1991

Miami, Florida

Professor Douglas H. Smith, Major Professor

The purpose of this investigation was to examine the characteristics of the successful small black-owned enterprises in Dade County, Florida. A descriptive and correlational research approach was employed in this study, in which there were two phases: an initial questionnaire study of 353 small black-owned businesses, and an interview study of 20 randomly selected most successful and 20 least successful small black entrepreneurs.

The main conclusions in the study are (1) the characteristics are not the same for all successful small black-owned firms, (2) success factors are not identical for all small black-owned firms, (3) the majority of small black-owned firms are deficient in critical successs factors, (4) the relationship between staff development, leadership styles, HRD skills and success is significant, (5) the majority of small black entrepreneurs are not extremely aware 
of the value of staff development to the success of their firms.

The recommendations for further research are (1) experimental studies need to be carried out to analyse further the relationship between HRD skills and success in black-owned firms as the findings of this study should be treated as exploratory, (2) to confirm or disconfirm the findings as, unlike this study, other studies have reported a significant relationship between certain selected critical factors and success in small firms, (3) to test the relationship between the awareness of staff development (as a success factor) and success in small black-owned firms, and (4) to examine further the relationship between leadership styles and success in small black-owned firms. 
FLORIDA INTERNATIONAL UNIVERSITY

Miami, Florida

A STUDY OF THE CHARACTERISTICS OF SUCCESSFUL SMALL BLACK-OWNED ENTERPRISES IN DADE COUNTY, FLORIDA

A Dissertation submitted to the College of Education in partial fulfillment of the requirements for the degree Doctor of Education

by

Granville Alfonso Dickson 
Copyright by

Granville Alfonso Dickson

1991 
A STUDY OF THE CHARACTERISTICS OF SUCCESSFUL SMALL BLACK-OWNED ENTERPRISES IN DADE COUNTY,

FLORIDA

By

Granville A. Dickson

This dissertation, having been approved in respect to form and mechanical execution, is referred to you for judgment upon its substantial merit.

Dean I. Ira Goldenberg

College of Education

The dissertation of Granville Alfonso Dickson is approved.

Robert S. Winter

Carlos M. Alvarez

Douglas H. Smith, Major

Professor

Date of Examination:

Dean Richard L. Campbell

Division of Graduate studies

Florida International University, 1991 
Dedicated to:

My wife Shirley and children Nicola, Deirdre-Anne, and Gregory 


\section{ACKNOWLEDGEMENTS}

The author wishes to express his appreciation to certain individuals for their significant assistance during the production of this dissertation. The author is particularly indebted to his doctoral committee - Dr Douglas Smith, Dr Carlos Alvarez, and Dr Robert winter - for their unflinching support, constructive criticism, and consistent understanding during the formulation and execution of this study.

Appreciation is expressed to Mr Francis J. Lamprea, Director of the Miami/ Fort Lauderdale Minority Business Development Center, for critiquing the questionnaire instrument, and providing a letter of support for the study. Appreciation is also due to Dr Paulette Johnson for her unfailing assistance in critiquing the questionnaire instrument, and in reviewing the appropriateness of the statistical techniques selected for this study. Gratitude is also due to Dr Minnie Dunbar and Mr Nagaraj Sivasubramaniam for their technical assistance in conducting the computer analysis for this study.

Finally, the author wishes to express his deep appreciation to his wife Shirley, for her continued support and understanding during the study. 
VITA

The author was born in Kingston, Jamaica, the son of Dewett Henry Dickson, public transport operator, and Louise Albertha Dickson. He received his basic education at Calabar High School. In 1959 he obtained the Bachelor of Arts degree from the University of London, majoring in Economics and History. In 1963 he earned the Diploma in Education from the University of the West Indies. The author gained in 1967 the professional degree of Associate of the Chartered Institute of Administration based in London, England. He graduated from Howard University in 1969 with the Master of Arts degree in Economics. In 1969 he gained the Diploma in Executive Development from the International Center for Advanced Technical and Vocational Training in Turin, Italy. The author earned in 1978 the Diplome in Export Training and Development from the World Trade Center in New York.

In 1989 the author was enrolled in the graduate program at the University of Miami, and in 1991 he obtained the Master of Science degree in Education. In 1991 he earned the the degree of Doctor of Education from Florida International University.

The author was a Lecturer at the College of Arts Science and Technology in Kingston, Jamaica, from 1964 to 1969. He was the Deputy Corporation Secretary at the Jamaica Development Bank from 1969 to 1971. From 1973 to 1986 he was the Director of the Small Businesses Development Center. 
TABLE OF CONTENTS

Page

Abstract i

Dedication iii

Acknowledgements iv

List of Tables $\mathrm{x}$

CHAPTER ONE. INTRODUCTION 1

Background to the Problem 3

Small Businesses in the United States 4

Small Businesses in Dade County, Florida 7

Black-owned Small Businesses in the United States 8

Black-owned Small Businesses in Dade County, Florida 12

$\begin{array}{ll}\text { Summary of the Background to the Problem } & 14\end{array}$

$\begin{array}{ll}\text { Purpose of the Study } & 15\end{array}$

$\begin{array}{ll}\text { Rationale for the Study } & 16\end{array}$

$\begin{array}{ll}\text { Major Questions and Hypotheses } & 17\end{array}$

$\begin{array}{ll}\text { Significance of the study } & 19\end{array}$

$\begin{array}{ll}\text { Definition of Terms } & 20\end{array}$

$\begin{array}{ll}\text { Assumptions } & 24\end{array}$

Limitations of the Study 25

CHAPTER TWO. REVIEW OF RELATED LITERATURE 26

$\begin{array}{ll}\text { Introduction } & 26\end{array}$

Empirical Studies Related to the Problem 26

Comprehensive Management Theory 26

Management of Small Enterprises $\quad 27$

Factors Critical to Success 28 
Small Business Failure

Training and Development

Summary of Review of the Literature

Introduction

Part One: Methodological Literature Review and Rationale 42

Review of Methodological Literature 40

Methodological Rationale

Part Two: The Base Data Survey (Phase One) 44

Target Population 45

Total Sample and Selection 46

Instrumentation selection

Null Hypothesis to be Tested in Phase one

Data Collection Procedures for Phase One

Construction of the Questionnaire

Preparation of the Cover Letter

Field-testing the Questionnaire

Determination of the Response Rate

Follow-up Activities

Treatment of Bias 50

Data Analysis and Interpretation

51

Part Three: The Interview Study (Phase Two) 52

Population and Total Sample for Phase Two

Null Hypotheses to be Tested in Phase Two 
Recording the Responses $\quad 55$

Field-testing the Interview Guide 55

Recruitment and Training of Interviewers 55

Data Analysis and Interpretation 56

CHAPTER FOUR. PRESENTATION AND ANALYSIS OF DATA 58

$\begin{array}{ll}\text { Introduction } & 58\end{array}$

$\begin{array}{ll}\text { Pilot study } & 58\end{array}$

$\begin{array}{ll}\text { Base Data Survey (Phase One) } & 60\end{array}$

$\begin{array}{ll}\text { Data Collection Procedures } & 60\end{array}$

$\begin{array}{ll}\text { Treatment of Bias } & 61\end{array}$

Summary Descriptive Data of Base Data Survey 62

Testing of the First Null Hypothesis 69

Interview Study (Phase Two) $\quad 77$

$\begin{array}{ll}\text { Summary Descriptive Data of Interview Study } & 77\end{array}$

Testing of the Second Null Hypothesis 108

Testing of the Third Null Hypothesis 116

Testing of the Fourth Null Hypothesis 126

Testing of the Fifth Null Hypothesis 128

$\begin{array}{ll}\text { Testing of the Sixth Null Hypothesis } & 130\end{array}$

Testing of the Seventh Null Hypothesis 131

$\begin{array}{ll}\text { CHAPTER FIVE. SUMMARY AND CONCLUSIONS } & 138\end{array}$

$\begin{array}{lr}\text { Introduction } & 138\end{array}$

$\begin{array}{ll}\text { Summary of the Study } & 138\end{array}$

$\begin{array}{ll}\text { Discussion of the Findings } & 141\end{array}$

$\begin{array}{lr}\text { Conclusions } & 150\end{array}$

Recommendations for Further Research 151 
APPENDIX A Schedule of Activities for Proposed Study 154 APPENDIX B Form Letter to Sample for Base Data Survey 155 APPENDIX C Letter of Endorsement from the Director of the Miami/Fort Lauderdale Minority Business Development Center

APPENDIX D Small Business Questionnaire 


\section{LIST OF TABLES}

Table

Title

Page

1. Population Projections for Dade County Made on April 1, 1989, for 1990, 1995 and 2000 ..... 7

2. Selected Characteristics of Small Businesses in 1983 . . . . . . . . . . . . 10

3. Categories of Services Used by Small Firms . . . . 33

4. Causes of Small Business Failure . . . . . . . 35

5. Factors Critical to Small Business Success Identified By Various Researchers . . . . . . . 39

6. Comparison of Early and Late Respondents to the Phase One Survey ............. . . . . 22

7. Periods of Time Black-owned Firms in Present Business . . . . . . . . . . . . . .63

8. Forms of Business Organization in Black-owned Firms 64

9. Major Business Activities of Black-owned Firms . . .65

10. Full-time Employees in Black-owned Firms . . . . .66

11. Part-time Employees in Black-owned Firms . . . . .66

12. Number of Years Net Profit Earned in Period 1985-89 by Black-owned Firms . . . . . . . . .67

13. Net Profit Earned in 1989 by Black-owned Firms . . .68

14. Comparison of Present Business and Success in Black-owned Firms . . . . . . . . . . 70

15. Comparison of Form of Business Organization and Success in Black-owned Firms . . . . . . . . .71 
16. Comparison of the Major Business Activities and Success in Black-owned Firms . . . . . . . . . .72

17. Comparison of Net Profit Earned in 1989 and Success in Black-owned Firms . . . . . . . . . .73

18. $t$-test of Differences Between the Most and Least Successful Blackoowned Firms on the Variables "Fu11-time Employees", "Part-time Employees". and "Number of Years Net Profit Earned". . . . . . .75

19. Staff Development as a Success Factor in Black-owned Firms . . . . . . . . . . . . 78

20. A Flexible Informal Control System as a Success Factor in Black-owned Firms... . . . . . . . 80

21. Close Unstructured Communication System as a Success Factor in Black-owned Firms . . . . . . . 81

22. Entrepreneur as Final Decision-maker as a Success Factor in Black-owned Firms . . . . . . . 82

23. Entrepreneurial Behavior as a Success Factor in Black-owned Firms . . . . . . . . . . . 83

24. Innovation as a Success Factor in Black-owned Firms ........................ . 84

25. Creativity as a Success Factor in Black-owned Firms . . . . . . . . . . . . . . . 84

26. Managerial Competence as a Success Factor in Black-owned Firms ................ . 85 
27 Masnagerial Skills as a Success Factor in Black-owned Firms . . . . . . . . . 86

28. Interpersonal Skills as a Success Factor in Black-owned Firms . . . . . . . . . . 87

29. Environmental Characteristics as a Success Factor in Black-owned Firms . . . . . . . . . . . 88

30. The Involvement of Top Management as a Success Factor in Black-owned Firms . . . . . . . 89 31. The Skills of Key Employees as a Success Factor in Black-owned Firms . . . . . . . . . . .90

32. The setting of priorities as a success Factor in Black-owned Firms ............. . 91

33. Maintenance of a Long Range Orientation as a Success Factor in Black-owned firms . . . . . . . 92

34. Availability of Venture and Reserve Capital as a Critical Factor in Black-owned Firms . . . . . . .94 35. Availability of Financial and strategic Planning Skills as a Critical Factor in Black-owned Firms . .95 36. Availability of Internal $R \& D$ as a Critical Factor in Black-owned Firms . . . . . . . . . 96 37. Availability of Modern Equipment as a Critical Factor in Black-owned Firms . . . . . . . . 96 38. Availability of Consultants as a Critical Factor in Black-owned Firms . . . . . . . . . . .97 
39. Availability of Departmentation Skills as a Critical Factor in Black-owned Firms . . . . . . .98 40. Availability of Managerial Skills as a Critical Factor in Black-owned Firms . . . . . . .99

41. Availability of Employee Skills as a Critical Factor in Black-owned Firms . . . . . . . . .100

42. Availability of Entrepreneurial Skills as a Critical Factor in Black-owned Firms ... . . . .01

43. Amount of Staff Training Provided in Period 1985/1989 by Black-owned Firms . . . . . . . 102

44. Awareness of the Role of Staff Development in the Success of Black-owned Firms ......... 103

45. Leadership Styles of Small Black Entrepreneurs . . .04 46. Effect of Leadership Styles on Success in

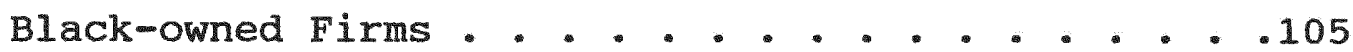

47. Types of Staff Training Provided by Black-owned Firms . . . . . . . . . . . . . .106

48. Staff Development Skills Within Black-owned Firms .107 49. t-test of the Differences Between the Most and Least Successful Small Black-owned Firms on Selected Variables ............ 109

50. Comparison of Venture/Reserve Capital and success in Black-owned Firms . . . . . . . . . 117

51. Comparison of Systematic Financial/strategic Planning and Success in Black-owned Firms . . . . .118 
52. Comparison of Internal $R \& D$ and Success in Black-owned Firm . . . . . . . . . . . 119

53. Comparison of Modern Equipment and Success in Black-owned Firms . . . . . . . . . . . . 120

54. Comparison of Consultancy Skills and Success in Black-owned Firms . . . . . . . . . . . .121

55. Comparison of Departmentation Skills and Success in Black-owned Firms . . . . . . . . . . 122

56. Comparison of Managerial Skills and Success in Black-owned Firms . . . . . . . . . . . .123

57. Comparison of Employee Skills and Success in Black-owned Firms . . . . . . . . . . . . .124

58. Comparison of Entrepreneurial Skills and Success in Black-owned Firms . . . . . . . . . 125

59. Comparison of Staff Development and Success in Blackmowned Firms . . . . . . . . . . . .127

60. Comparison of Staff Training and Success in Black-owned Firms . . . . . . . . . . . 128

61. Comparison of the Awareness of Contribution of Staff Development (to Success) and Success in Black-owned Firms . . . . . . . . . . . . 129

62. Comparison of Styles of Leadership and Success in Black-owned Firms . . . . . . . . . 131

63. Comparison of Selected Human Resource Development (HRD) Skills and Success in Black-owned Firms . . .133 


\section{CHAPTER ONE. INTRODUCTION}

In recent years there has been increasing emphasis in the United States on the need to expand and diversify the small business sector of the national economy. The sector is credited with significant contributions to the economic well-being of the United States in the areas of employment creation, economic growth, income generation and the development of technology (Steiner \& Solem, 1988). Ibrahim and Goodwin (1986) state that the success of the small business sector is important to both the stability and well-being of the economies of the United States and Canada. The contribution of the small business sector to the stability and growth of the American economy is related to the success of the individual enterprise. Nadler (1986) notes that all organizations, both the successful and the unsuccessful, commence their operations with three basic inputs for success: financial resources (money and securities), physical resources (equipment, tools, facilities), and human resources (the employees). Nadler (1986) observes that:

The management team had to develop and manage these three critical resources. If an organization's success is equated to the achievement of goals, as it certainly should be, the enterprise achieves that mission through well-developed and well-managed resources. Hence, the ultimate responsibility for an organization's success 
rests with its managers $(\mathrm{p} .2)$.

Nadler (1986) links human resource development (HRD) to the successful operation of a business when he views HRD as: A comprehensive learning system for the release of the organization's human potential - a system that includes both vicarious (classroom, mediated, simulated)

learning experiences and experiential, on-the-job experiences that are keyed to the organization's reason for existence (profit, survival, service, product, and so on).

In the case of small enterprises, viability is also dependent on the factors outlined by Nadler - financial resources, physical resources, and human resources. The small entrepreneur has little or no control over the availability of capital and physical resources. However, it can be argued that the small entrepreneur can directly promote the success of the firm through the provision of critical factors. The latter include staff support and development, the product of HRD programs. The adequacy of such programs depends partly on the availability of HRD skills within the firm.

Ibrahim and Goodwin (1986) report that entrepreneurial behavior, managerial skills, and interpersonal skills are key factors in the succes of small firms. This proposition is reinforced by the findings of Evans and Evans (1988) that the success of small manufacturing firms is largely influenced by the participation of top management at all levels of the 
enterprise, and by the skills of key personnel. Although there is no single cause of small business success (Carter, 1974), some researchers regard managerial and entrepreneurial skills as crucial variables in the viability of small firms (Holbek, 1975; Fisseha, 1982; Hope, 1983).

The foregoing factors are also relevant to successful small black-owned enterprises. In this study the primary question examined is the characteristics of successful small black-owned enterprises in Dade County, Florida. The general characteristics of small black-owned businesses are analysed. Critical factors essential for success are examined. The relationship between the quantity of critical factors and success in small black-owned firms is evaluated. Staff development as a determinant of success is assessed; and the awareness of its impact on success determined. The relationship between leadership styles and success in small black-owned firms is analysed. Finally, the relationship between HRD skills and success in small black-owned enterprises is evaluated.

\section{Background to the Problem}

As a framework for the study, it is important to review the different settings within which small firms operate. In this section, the general population of small enterprises in the United States is discussed, and the status of the small business sector in Dade County, Florida, is examined. A brief description of small black-owned enterprises in the United 
states is provided. Finally, an analysis of small black-owned businesses in Dade county is presented.

\section{Sma11 Businesses in the United States}

Chilton (1984) states that small enterprises account

for approximately 38 percent of the gross national product of the United States. However, they receive only $23 \%$ of total federal expenditures on goods and services. One of the most important efforts to channel more procurement funds to small firms is entrenched in Public Law 95-507 enacted in 1978 . One of the principal provisions of the law is that small firms receive al1 federal contracts of $\$ 10,000$ or 1 ess ( $10 \%$ of total federal purchases). The law also requires all contract bids over $\$ 500,000$ to include a plan to subcontract sections of the work to small businesses.

Toncre (1983) notes that as the American economy expanded in the 1980s, there was the expectation in government circles that the small business sector would play a more dynamic role in the process of economic growth. The Economic Report of the President to the Congress (1987) states that in 1986 stable prices, low interest rates, and continuous development provided a setting in which sma11 businesses could flourish. The state of the small business sector in the United states was robust at the end of 1986 , the fourth straight year of economic growth. Economic accomplishments during the period from fourth quarter 1982 to fourth quarter 1986 involved a $17 \%$ expansion in real GNP, a 
$26 \%$ increase in manufacturing production, and only a $13.3 \%$ rise in the general price level.

The Economic Report also indicates that small business formation was active in 1986, particularly in the trade and service industries. The national trend toward larger firms and the accompanying decline in small enterprises was arrested and temporarily reversed. Large business dominated sectors such as manufacturing lost employment, whereas small business dominated industries such as trade and services gained employment.

The Economic Report of the President to the Congress (1987) also indicates that there were 842,000 minority-owned enterprises in the United States in 1986. Of these 255,642 were owned by Asians, 339,239 by blacks, and 248,141 by Hispanics. About $1.8 \%$ of the minority population were entrepreneurs in 1982, compared to $6.9 \%$ of the nonminority population. Over $94 \%$ of the minority firms - as compared to $69 \%$ of the nonminority enterprises - were sole proprietorships.

The Economic Report of the President to the Congress (1989) states that small businesses led the way in job creation. Employment in small business dominated industries had increased by $4.9 \%$, while employment in large business dominated industries had grown by only $3.3 \%$. The number of small businesses continued to increase. Over 19 million nonfarm business tax returns were filed in 1988, compared to 
13 milion in 1980. Returns were filed by 4 million

corporations, 1.8 million partnerships, and 13.2 million sole proprietorships. Fewer than 7,000 of these enterprises were regarded as large businesses if an employment cut-off of 500 employees were used to define small and medium-sized firms.

Despite the growth in the number of small enterprises, small business failures have continued at a relatively high rate. Recent data suggest a failure rate of about seventy percent (Steiner \& Solem, 1988). Ibrahim \& goodwin (1986) stated that Dun and Bradstreet reports predicted that only one of three firms starting business in 1986 would still be in business at the end of 1990

Certain facilities have been instituted in the united States to minimize the incidence of small business failure, and to promote the growth and development of the sector. The chief agency established is the Small Business Administration (SBA). This is a federal agency set up in 1953 to protect and assist America's premier resource - small business. The SBA has more than 100 offices throughout the country, and a permanent staff of about 3,600. The SBA has many co-sponsored projects with private companies, colleges and universities. It also has some successful volunteer programs, such as the Service Corps of Retired Executives (SCORE).

In its effort to promote small business development, the support of the SBA has been focused on the following areas:

1. Business Development - management assistance through 
training, consulting, information, and conferences.

2. Financial Assistance - Ioan guarantees, bonding assistance, and other direct and indirect financial support.

3. Contract Assistance - helping small enterprises to obtain government contracts.

4. Advocacy - representing small business interests before Congress and other federal agencies.

Small Businesses in Dade County. Florida

Dade County is the county with the largest population in Florida. The Metro-Dade County Planning Department (1985) reports the size of the population in recent decades as $1,267,792$ in $1970,1,625,781$ in 1980 , and $1,780,000$ in 1984. The projected populations in Dade County for 1990, 1995 and the year 20000 are presented in Table 1.

Table 1

Population Projections for Dade County Made on April 1. 1989. for 1990, 1995, and 2000

$\underline{\text { Years }}$

1990

1995

2000
Projections

$1,889,039$

$1,996,431$

$2,083,029$

Source: 1989 Florida Statistical Abstract

As indicated in Table 1, it was anticipated in 1989 that 
the population for Dade County would rise steadily from 1990 until the year 2000 .

Metro-Dade Comprehensive Annual Financial Report (1987) states that Dade County in recent years has started to shift from a tourist-oxiented economy to one in which there is a widely diversified economic substructure. Industry and manufacturing are vibrant economic subsectors in Dade County. The share of Dade County in the growing tourist trade of Florida is one of its major economic forces. However, its attractiveness as a residential area to skilled labor, and its selection as the location for major and smaller light industries have combined with tourism to create a diversified economic base.

In Dade County, the SBA provides small entrepreneurs with its standard services. There are also local chambers of commerce of which a minority of small entrepreneurs are members. In addition, the Small Business Development Center (SBDC) is located at Florida International University in Miami. The SBDC provides services which include (a) general consultation (b) training programs (c) an Innovation Program which gives marketing and technical assistance to inventors, and (d) the International Trade Center designed to assist firms interested in importing/exporting. 
Black-owned Enterprises in the United States

In order to gain an adequate understanding of the relative position of the black small business sector in the American economy, it is necessary to describe briefly the setting in which it operates. The Bureau of the Census (1987) points out that in 1987 there were $424,165 \mathrm{black}$-owned firms in the United States, a significant decline from the 561,395 enterprises indicated in the 1977 census. However, Dingle (1986) reports that since 1982 black-owned firms have grown faster than the business sector as a whole, becoming less dependent on black consumers for their sales. For example, the largest black-owned industrial and service companies in the United States grew $14.4 \%$ in revenue in 1988, surpassing the $7.6 \%$ growth of the Fortune 500, according to Black Enterprise magazine's annual list of the 100 biggest black-owned businesses (1989; May. Sun Sentinel, p.1.). Moreover, black-owned firms have been exhibiting a slightly more diversified pattern of activity.

Table 2 presents selected characteristics of black and nonminority businesses in the United States for 1983. The characteristics highlighted are entrepreneurial experience and type of education. Table 2 shows that black entrepreneurs tend to have more business experience, more college education and complete more vocational courses than the owners of nonminority small businesses. Black entrepreneurs and nonminority business owners are comparable on the other 
characteristics.

Table 2

Selected Characteristics of Small Businesses in 1983

Characteristics

Nonminorities

Blacks

Entrepreneurial Experience:

Business Owner

$15.4 \%$

$14.8 \%$

Employee

$11.6 \%$

$11.4 \%$

Manager

$22.0 \%$

$27.4 \%$

Education:

Mean Years of School

$15.2 \%$

$15.6 \%$

Type of Education:

some college

$79.0 \%$

$84.0 \%$

Business Courses

$51.5 \%$

$51.3 \%$

Vocational courses

$44.9 \%$

$57.1 \%$

Source: JACA Corp., 1986.

Dingle (1986) observes that black firms might experience severe difficulties in the future. Although the Small Business Administration was not abolished in FY 1986, both the House and the Senate approved appropriation bills which cut the expenditures of the agency by $10 \%$, and dropped some programs completely. The result is that the fee for the guaranteed Ioans of the Small Business Administration has increased from one percent to two percent; while the guarantee has been reduced from $90 \%$ to $80 \%$. Simultaneously, 
expenditures for the SBA's direct lending program have been slashed from $\$ 257$ million to $\$ 101$ million.

Dingle (1986) also argues that in the future it would be more difficult for small black entrepreneurs to obtain financing from the private banking sector, which has become rather conservative. Brimmer (1987) reports that most small black-owned enterprises are still dependent on the black community for their survival and prosperity. Hylton (1988) points out that when the focus is on the international economy, increased foreign competition, tight markets, and sluggish economic growth have been observed. Black-owned enterprises must adapt to this exacting situation to ensure their future survival and prosperity. Over the past decade the penetration of the American market by foreign competitors has constantly increased. It is expected that this trend would continue in the future.

Hylton (1988) also argues that American corporations must adopt inventive management techniques, and develop innovative products, in order to compete successfully in the international market. Producers in some Asian countries such as Japan, Taiwan, Singapore and Korea, manufacture various high quality products with greater cost efficiency than their competitors in the United States. This situation provides a major challenge to black-owned businesses, which must improve their competitive position in order to survive and grow. Hylton (1988) reports that black firms represent less 
than $5 \%$ of all enterprises. As black-owned firms venture into general markets in their effort to achieve growth and diversification, the quality of their managerial talent is expected to become even more crucial. There is a need for a larger pool of top management talent in the black business sector. This situation underscores the urgent need for staff development in black enterprises in order to ensure their survival and success.

Black-owned Small Enterprises in Dade County. Florida Thomas (1988) stated that in 1977 the number of black-owned enterprises in Dade County was 2,148 , with the figure rising to 3,885 in 1982. The Metro-Dade County Planning Department (1986) reported that blacks accounted for approximately $18 \%$ of the County's population, yet owned only one percent of the business entities in 1986, the same as in 1977. The majority of the black-owned firms were then in the city of Miami. They were usually small in size, and largely owner-operated with no employees. Generally, the black-owned firms which employed workers had one-third the number of employees as the average Dade County enterprise. The Metro-Dade County Planning Department (1986) also pointed out that below average pay scales combined with low employment levels to produce low payroll generation for the average black-owned business.

The Metro-Dade Office of Black Affairs (1987) reported that small black-owned enterprises in Dade County, Florida, 
were concentrated in a variety of service-oriented industries. Those included automobile maintenance, personal services, home improvement/ maintenance, construction trades, engineering/electrical services, professional services, wholesaling/retailing, import/export, and educational services.

The Metro-Dade Office of Black Affairs (1987) also stated that in 1981 only about two percent of the total spending of Dade County for major services was channelled to black-owned enterprises. Simultaneously less than four percent of Dade County's construction contracts was allocated to black-owned firms. Consequently, the Metro-Dade Commission set up a Black Business Participation Task Force to conduct a disparity study. On November 3, 1981, the Metro-Dade Commission endorsed the findings of the Task Force which indicated that black-owned businesses had not participated proportionately in the economic development of Dade County. The Metro-Dade Commission authorized the formulation of programs and measures to improve the situation in which black-owned enterprises operated.

On May 4, 1982, the Metro-Dade Commission approved an ordinance whereby firms submitting bids for contracts in respect to professional architectural, engineering, architectural landscaping, and land surveying services, had to incorporate an affirmative action plan before being certified by the county. 
On May 18, 1982, the Metro-Dade Commision approved an administrative order requiring each county department to formulate a percentage goal for utilizing black-owned enterprises that provided professional services. The order recommended a goal of granting $17 \%$ of all professional service contracts to black-owned businesses, but permitted each department to fix its own target based on the kind of services required, and the availability of capable black-owned businesses to meet the needs identified.

In addition to the services of the SBA and the SBDC, black entrepreneurs in Dade County might also use the services of the Miami/Fort Lauderdale Minority Business Developoment Center. That organization provided assistance in the areas of planning, management, procurement/construction, finance, exporting, marketing, and computer data systems.

\section{Summary of the Background to the Problem}

The crucial role of the small business sector in the growth and development of the American economy has been noted. The success rate among small businesses has had a positive impact on the performance of the national economy. Small firms have more control over the use of human resources than over the other two inputs for success--financial resources and physical resources. The small entrepreneur can use skills at all levels within the firm to achieve success in business. Hence, the capacity to create the needed skills has a direct relationship to success. The federal government 
has recognized the role of small businesses in national development, and accordingly has supplied substantial resources through the Small Business Administration.

Despite this support, the rate of failure among small enterprises continues to be high. This experience has been particularly evident for small black entrepreneurs throughout the United States due to contraction in federal funding in the 1980s, increased competition, tight markets, sluggish economic growth, and a shortage of entrepreneurial, managerial, and other skills at all levels within the firm.

In Dade County, certain facilities are in place to assist small entrepreneurs in their effort to achieve survival and success. Small black-owned businesses account for a fraction of the firms in Dade county. It is important to investigate the characteristics of successful black-owned enterprises. This knowledge would contribute to the growth and development of the black small business sector in Dade county.

\section{Purpose of the Study}

The main purpose of this study is to examine the characteristics of the successful small black-owned enterprises in Dade County, Florida. The focus is on the relationship between the characteristics and success, and not on any causal relationship there might be between them.

A few studies have examined the relationship between critical factors and success in the operation of black-owned 
small enterprises. These are extensively discussed in the next chapter, the review of literature. However, there is a dearth of research on the characteristics of successful small businesses, especially black-owned businesses. This study attempts to give direction to future causal-comparative and experimental research on the characteristics of small black-owned enterprises.

\section{Rationale for the Study}

This study was undertaken for five specific reasons:

1. The problem is of direct interest to the investigator, as it is related to his professional background. He was trained as a small business consultant, and worked for ten years as the Executive Director of the Small Businesses Development Center in Kingston, Jamaica.

2. The study has theoretical and practical significance. It is anticipated that the insights gained concerning the relationship between critical factors and success in small black-owned firms would contribute to the development of a comprehensive theoretical framework which could be used to more effectively analyse the multiplicity of problems facing small entrepreneurs in general, and small black entrepreneurs in particular.

3. The small black business sector in Dade County, Florida, has the potential for growth and development. It is hoped that the emphasis on critical factors in this study would stimulate their introduction in small enterprises in general, 
and small black-owned firms in particular.

4. The problem is researchable in that the required data could be collected and analysed. The subjects are accessible, they have the needed information, and an appropriate data collection instrument could either be identified or developed.

5. There is still need for extensive research in all areas of small business operations (d'Amboise \& Muldowney, 1988).

It is the hope of this study that the results would contribute to a greater understanding of the characteristics of successful small black-owned firms. From that base of information, specific guidelines could hopefully be established for the development of those resources for all people wanting to take the step into entrepreneurship, particularly blacks.

\section{Major Questions and Hypotheses}

Many studies such as those by Udell (1978) and chang (1986) have concluded that small enterprises are usually unsuccessful due to a combination of factors. Other studies such as those conducted by Holbek (1975), Fisseha (1982), Hope (1983), and Dickson (1983), have advanced the proposition that a deficiency of management skilis is the principal cause of failure in the small business community. Researchers such as Nicholson (1983), Ibrahim \& Goodwin (1986), Olson (1987), and Thomas (1988) have discussed many characteristics of the successful small entrepreneurs. 
From these collective studies, which are further discussed in the next chapter, the primary research question and seven specific secondary questions have been developed, and they form the framework of this study. The primary question in this study is as follows: What are the characteristics of successful small black-owned firms?

In order to effectively answer the primary question, the following seven secondary questions have been formulated:

1. What are the general characteristics of small black-owned firms?

2. What critical factors are essential for success in small black-owned firms?

3. Is there any relationship between the amount of critical factors and success in small black-owned firms?

4. Is staff development one of the determinants of success in small black-owned firms?

5. If so, are small black entrepreneurs aware of the role of staff development in the success of their firms?

6. Does the leadership styles of small black entrepreneurs affect success in their firms?

7. Is there any relationship between HRD skills and success in small black-owned firms?

From the foregoing questions emanate the following seven null hypotheses:

1. The general characteristics are the same for all 
successful small black-owned firms. This null hypothesis addresses question one.

2. The critical factors essential for success are identical in all small black-owned firms. This null hypothesis addresses question two.

3. There is no relationship between the amount of selected critical factors and success in small black-owned firms. This null hypothesis addresses question three.

4. Staff development is not one of the determinants of success in small black-owned firms. This null hypothesis addresses question four.

5. Small black entrepreneurs are not aware of the role of staff development in the success of their firms. This null hypothesis addresses question five.

6. The leadership styles of small black entrepreneurs do not affect success in their firms. This null hypothesis addresses question six.

7. There is no relationship between HRD skills and success in small black-owned firms. This null hypothesis addresses question seven.

\section{Significance of the Study}

In the 1970 s and 1980 s many research studies and articles had addressed the various aspects of small enterprises, including the problems which often resulted in bankruptcies in the sector. Vozikis (1979) noted that there was a lack of empirically-based normative or descriptive 
studies concerning the internal problems of small firms, as most empirical research had dealt ex post with causes of small business failure or success.

In view of the high incidence of failure in the small business sector, more research into the characteristics of small business success is required. More emphasis on success factors would enhance the rate of survival among small businesses, thereby increasing their impact on development in Dade County, Florida. Small firms have little control over the environmental variables affecting their operations such as market prices, market share, and production costs. However, the quality of the human resources in the firm determines significantly how the environmental factors are handled. The extent to which a small firm undertakes staff development determines its capacity to relate to the exogenous forces in the economy. This study is partly designed to determine the degree to which selected critical factors would assist the small entrepreneur in successfully managing the firm.

If the relationship between specific small business characteristics and success is found to be very significant, the former could be used to predict success in black-owned small enterprises.

\section{Definition of Terms}

The following definitions were designed to facilitate the operational purpose and limitations of this study: 


\section{Critical Factors}

Critical factors are those that are considered vital to the growth, development and success of a small business, such as leadership style, staff development, availability of HRD skills.

\section{Human Resource Development/Staff Development}

Human resource development (HRD) is defined as a system of staff development whereby the employees in an organization are equipped with the requisite skills for efficiency and growth. HRD is composed of the functions of training, education, and development.

\section{Training}

Nadler (1986) states that training involves the provision to the individual of the skills, knowledge and attitudes required to perform the job the worker is currently engaged to do. The primary responsibility of the small entrepreneur is to manage the enterprise efficiently. Initially, the small entrepreneur cannot afford to set up separate departments in the firm, and employ professional staff to perform the various functions. Consequently, the small entrepreneur has to acquire the requisite managerial skills in order to effectively supervise and train the employees. The managerial skills which the small entrepreneur needs in order to run his business are in the areas of planning, organizing, staffing, directing, and controlling. 


\section{Education}

Nadler (1986) defines education as the preparation of the individual for the performance of an identified job within the organization in the near future. As the business expands and grows over time, HRD activities in the area of education prepare the small entrepreneur and senior personnel to manage a business with various departments. As the firm becomes more complex and unwieldy, the entrepreneur assigns responsibility for different functions to the departmental managers who need the relevant skills to perform their roles in areas as marketing, production, finance and accounting.

\section{Development}

Nadler (1986) defines development as the process whereby the individual is provided with the necessary skills so that he might move with the organization as it grows and develops over time. Skills pertaining to development include research, forecasting and planning.

\section{HRD Skills}

The HRD skills that are required within the firm to successfully design effective and efficient learning programs are the following:

i. Determine projects appropriate for instructional development.

ii. Conduct needs assessments.

111. Assess learner characteristics.

iv. Analyse the structural characteristics of jobs, tasks, 
and content.

v. Write statements of learner outcomes.

vi. Analyse the characteristics of a learning environment. vii. Sequence learner outcomes.

vii. Specify instructional strategies

ix. Sequence learner activities.

x. Determine instructional resources appropriate to instructional activities.

xi. Evaluate instruction.

xii. Create course, learning package, and workshop management systems.

xii. Plan and monitor instructional development projects. xiv. Communicate effectively in visual, oral, and written form.

xv. Demonstrate appropriate interpersonal, group process, and consulting behavior.

\section{Net Profit}

Net profit is the surplus after total expenses (including overheads) have been deducted from total revenue.

\section{Success}

For the purpose of this study, success is presented in three categories. Firstly, the most successful small black firm is one which has been in business for a minimum of five years, during which it generates a net profit for the entire period. Secondly, the less successful small black firm is one which has been in business for a minimum of five years, 
but has earned a net profit for three to four of the previous five years. Thirdly, the least successful small black firm is one which has been in business for at least five years, but has realized a net profit for only up to two of the previous five years.

\section{SmaIl Business}

A small business is one in which the entrepreneur, even if assisted by a skilled professional staff, is in control of the decision-making process. Such a firm has gross annual sales up to $\$ 5$ million, and a workforce of 100 or less.

The terms small business, small enterprise, sole proprietorship, and small firm are used interchangeably throughout this study.

\section{Assumptions}

The following assumptions were made for the purpose of this study:

1. Small black entrepreneurs in Dade County, Florida, were basically desirous of success in their business endeavours.

2. The relationship between critical factors and success was measureable.

3. Access to developmental facilities in Dade county, Florida, was based on the principle of equal opportunity.

4. Smali black entrepreneurs in Dade County, FIorida, were willing to implement appropriate strategies to attain success in their firms.

5. Employees in small black-owned enterprises had the 
academic and attitudinal prerequisites to benefit from the application of HRD skills.

6. Successful small black entrepreneurs possessed the requisite leadership skills.

\section{Limitations of the study}

The following factors are considered constraints on the generalizability of the results of this study:

1. Since a number of factors might influence the success of black-owned small enterprises, the generalizability of the results of the study is limited.

2. This study is mainly concerned with the characteristics of successful small black-owned enterprises, and not with any causal relationship between the characteristics and success.

3. The researcher has no control over the setting for this study, and is only measuring what already exists.

4. The data collected in this study were based on the perceptions of the situation by the subjects. 


\section{CHAPTER TWO. REVIEW OF RELATED LITERATURE}

\section{Introduction}

The study of the characteristics of successful small black-owned enterprises in Dade County, Florida, calls for a review of pertinent literature concerning small enterprises. The selection of the Iiterature is intended to provide a background of knowledge essential to an understanding of the objective of this study.

This chapter is organized into two parts. The first part contains an analysis of previous empirical studies which are related to the problem of this study. The question of a comprehensive management theory for small business is examined. Studies related to small business management, the factors critical to success in small businesses, small business failures, and training and development are reviewed. The second part provides a summary of the literature review.

Empirical studies Related to the Problen

The empirical studies related to the problem being addressed in this study are reviewed under the captions presented in this section.

\section{Comprehensive Management Theory}

A study by d'Amboise and Muldowney (1988) stated that all areas of small business management were still in need of in-depth investigation. No comprehensive management theory for small business existed, and no all-encompassing theoretical framework capable of explaining the management of 
small firms. Typologies had been developed in several of the areas investigated which yielded a number of relationships among many variables. Those relationships could be utilized as indicators of the functioning of small businesses. The typologies developed might be viewed as important efforts at theory building, which could result in the formulation of worthwhile constructs.

\section{Management of Smal1 Enterprises}

Holbek (1975) regarded management as a crucial variable in the economic effectiveness of small firms. Pecorella (1978) proposed a methodology to describe current-value human resource accounting (HRA) to aid management in decision-making, and generate information concerning the effects of organizational policies and practices on the value of the organization's human resources. A two-phase study was developed to investigate the nature of the relationship between the human organization and organizational effectiveness. Results indicated that even small changes in the human organization could yield significant increases or decreases in future performance.

Hope (1983) stated that most researchers maintained that certain aspects of small business management could be taught including finance, cash flow analysis, marketing, business formation, and business proposal preparation. ConsequentIy, higher education might be a significant contributing factor to performance and success in small 
business. Hope (1985) also noted that the participants in the study believed that their education contributed to their success, and stressed the need for practical courses.

\section{Factors Critical to Success}

Nicholson (1983), in discussing the concept of excellence in managing a small business in the rapid growth stage, identified certain traits of the successful small entrepreneur. They included independence, motivation, creativity, and communication skills. The study cited statistics which indicated that the successful entrepreneur was not necessarily a supernaturally gifted young person with little formal education or company experience. Rather, excellence in the rapidly growing business might demand both a new style of management and luck. The entrepreneur might acquire appropriate managerial skills through training, education and development, the strategies used in HRD.

Success in business was the major objective of a small entrepreneur. OIson (1987) stated that the start-up phase of a small business was critical to its eventual survival and success. During that phase, the desirable traits of key personnel included (a) role orientation, (b) a high tolerance for ambiguous, unstructured situations, (c) an ability to adopt the long-range view, (d) a willingness to assume moderate risk, (e) both intuitive and analytical skills, and (f) a high need for achievement. Such attitudes and skills are usually the products of a human resource development 
program which is indispensable in the modern small business.

Olson (1987) reported that during the start-up phase, the entrepreneurial firm had few divisions. The factors that could increase the firm's chances for success included (a) employees who were generalists (b) a flexible, informal control system, (c) a close unstructured communication network, and (d) location of the final decision authority with the entrepreneur. Olson (1987) also noted that in the firm's growth phase, the emphasis shifted from conceptual development to the creation of organizational systems and processes which promoted more effective utilization of innovative ideas. Design changes during the growth phase included (a) the establishment of various functional departments, (b) the introduction of work routines requiring specialized skills, (c) the development of hierarchical decision mechanisms, and (d) the installation of quasi-formal control rules.

In a study carried out by Ibrahim and Goodwin (1986), a set of variables associated with a successful small business were identified. The results indicated that entrepreneurial behavior, as measured by the personality attributes, was perceived as the key success factor in small businesses. That finding was consistent with, and supported by, other related studies which concluded that personality traits (risk taking, autonomy, change, cognitive structure, innovation) were important dimensions in identifying 
successful entrepreneurs from the general population (Brockhaus, 1980; Sexton and Bowman, 1983). Chaganti and Chaganti (1983) argued that in respect to "profitable and not-so-profitable small business", innovation, creativity, and managerial competence were key success factors for small businesses.

A second key success factor identified by Ibrahim and Goodwin (1986) was the concept of managerial skills. That conclusion was supported by previous research (Khan \& Roca, 1982: Chaganti \& Chaganti, 1983), which suggested that managerial competence and niche strategy were among the principal features of successful small firms.

Two other important but less significant success factors, highlighted by Ibrahim \& Goodwin (1986), were interpersonal skills and analysis of environmental characteristics. Those findings emphasized the need for training in strengthening the skills of the personnel in communication and environmental analysis. The findings supported the proposition that there was a high correlation between staff development and success in small enterprises. The arguments about small business success in general are also relevant to black small enterprises. Thomas (1988) reported that black entrepreneurs cited the following factors as important for success: reliable employees (96.2\%), knowledge of market ( $90.6 \%$ ), available operating capital (88.7\%), dedicated employees (83\%), trained managers (82.4\%), 
trained employees $(78.8 \%)$, access to capital (77.8\%), terms of loan (74\%), cost of capital (74\%), knowledge of competition (69.2\%), set asides (66\%), size of loan (66\%), fair competition (64.6\%), credit required (64\%), equity/assets required (64\%), technical assistance (62\%), educated employees (61.5\%), location (61.5\%), better segmentation of the market $(61.2 \%)$, better advertising $(60.8 \%)$, collateral required $(59.2 \%)$, and an open market (58.3\%). A review of the latter data emphasized the significance of the quality of human resources to the success of small businesses.

Evans and Evans (1988) attributed the success of a small manufacturing enterprise to four factors: top management involvement at all levels of the operation, the upgrading of the skills of the key personnel, new reporting procedures, and the firm's close relationship with the local college. These findings underscore the significant role of HRD activities in the success of the small firm.

Thomas \& Evanson (1987) investigated the relationship between the use of financial ratios and small business success. Regression analysis failed to indicate any significant relationship between the number of financial ratios used in decision-making to either earnings or total earnings to sales. However, the findings did establish the importance of location to the survival of a retail business. 
In a study conducted by Steiner \& Solem (1988), it was found that age and education of the manager were not related to the success of the firm. However, managerial experience and prior experience in a similar or identical type of business might contribute to the successful operation of the business. In the study, all of the successful firms' owner/managers had prior managerial experience, as compared to three quarters of the less successful owner/managers.

Schilit (1986), in a study of entrepreneurial success, delineated certain guidelines for growth which included (a) learning to set priorities from the earliest stage of the business, (b) monitoring the business environment constantly, (c) maintaining a long-range orientation, avoiding too much reliance on logic, (d) encouraging entrepreneurial thinking throughout the business. Such skills and attitudes were best generated by a HRD program designed to satisfy the specific needs of the individual firm.

Rock (1987) noted that the difficulty inherent in the day-to-day decisions required in managing a small business was one explanation as to why some entrepreneurs succeeded and others failed. A business plan provided an instrument to evaluate the performance of the entrepreneur. Rock (1987) pointed out further that a new firm would experience problems If it lacked a rigid accounting department. Commitment to the business is vital, and the entrepreneur must be objective in evaluating the firm's progress. Rock (1987) also concluded 
that the characteristics of a successful small entrepreneur included (a) knowing whom to listen to and when, (b) knowing which questions to ask, and (c) knowing when to bring in outside skills, and the types of skill needed.

Roitman et al (1984) reported that a group of executives identified the services shown in Table 3 as being essential. Table 3

Categories of Services Used by Small Firms

Categories

Financial Management

Business Management

Technical Assistance

Marketing

Personnel Management

Information Clearinghouse
Percent of Total

23

23

19

14

12

$\underline{8}$

Total

100

Table 3 indicates that no single type of service appeared to be more significantly requested than the others. However, integrating financial management, business management, marketing and personnel into a single category relating to the small business management function indicates that direct business services were often classified as useful by the respondents. In comparison, technical assistance services were cited relatively infrequently. Consequently, it 
was concluded that staff development was a vital element in the successful operation of small enterprises.

Carter (1974), after a study of a number of firms receiving various forms of assistance from the Small Business Administration (including technical assistance, financial assistance and the award of non-competitive, negotiated contracts for government procurements), concluded that there was no single cause of success in small firms.

\section{Smal1 Business Failure}

Udel et al (1978) identified a number of causes of small business bankruptcies, which included failure to accomplish systematic financial and strategic planning, insufficient internal Research and Development ( $R$ \& D), lack of modern equipment, and inability to keep abreast of state-of-the-art technological developments. Udel et al (1978) argued that, to varying degrees, those deficiences were traceable to one cause - inadequate financial and human resources. Robinson (1979) observed that the extensive use of consultants was beyond the financial capability of small entrepreneurs. Rimler et al (1976) stated that most small firms could not afford to establish separate internal departments. The small entrepreneur was compelled to assume a variety of roles, frequently failing to delegate tasks which could be better performed by others. Consequently, the small entrepreneur in the highly complex, competitive modern economy needed a variety of management skills for survival and success. 
Edmonds (1979) reported that in nearly half (44.4\%) of the cases, managerial incompetence of small black entrepreneurs was a major cause of failure as shown in Table 4. Other important causes of failure were unbalanced experience (19.9\%), lack of managerial experience (17.2\%), and lack of experience in line management (9.8\%). Such deficiences in the management of small black-owned firms indicate the need for more emphasis on staff development. Table 4

Causes of Small Business Failure

Causes

Incompetence

Unbalanced experience

Lack of managerial experience

Lack of experience in Iine

Neglect

Fraud

Disaster

Unknown Cause

\section{Percent}

44.4

19.9

17.2

9.8

3.0

1.3

0.8

$\underline{3.6}$

Total 100.0

Minks (1980) observed that many entrepreneurs were not able to differentiate between generalized symptoms and specific problems of their firms. Therefore, appropriate 
actions could not be taken in time to prevent failure. Goad (1980) noted that many small firms got into difficulties because they had not used organization development techniques in the solution of management problems. Chang (1986) revealed that common factors contributing to business failures were competition and the lack of venture and reserve capital.

Hambrick and Crozier (1985) suggested that many rapid growth firms failed because of mismanagement. Managing the small enterprise with an emphasis on rapid growth required (a) a chief executive who had the capacity to perceive the firm as a larger entity, (b) the early engagement and development of the team needed for the future, and (c) consistent reinforcement of the original core vision of the firm. Such tendencies and capacities could be created and nurtured within the small firm by an appropriate HRD program, particularly the development component.

other researchers identified specific causes of small business failure. Howatt (1978) found that small businesses had a difficult time obtaining sufficient operating capital. Fisseha (1982) and Dickson (1983) identified the deficiency of management skills as a major problem facing small businesses in general, especially manufacturing enterprises. Insufficient managerial skills were identified by Wichman (1983) as the most prevalent cause of small business failure. Hope (1983) argued that entrepreneurial training was instrumental in preventing failure. Kent (1986) reported that 
the aggregate level of business failures was a function of business Iiquidity.

\section{Training and Development}

Budke and Kerka (1988) reported that training and development professionals performed a key role in assisting people to improve their performance by utilizing all aspects of the work environment. Those professionals were debating the existence of an integrated theoretical framework, and how it might support practice in their field. Human Performance technology (HPT) had been proposed as a systems-based field of study for training and development. The goal of the HPT field was to employ a systems approach to staff development to ensure that the employees had the knowledge, skills, motivation and environmental supports required to do their jobs effectively and efficiently. In regard to professional preparation, academic programs for training and development should be based on a set of core competencies and a unique theoretical base such as human performance technology.

The existence of adequate HRD skills within the small enterprise is likely to ensure the suitability of training programs. Dickson (1983) stated that training programs should be directly applicable to small firms, and trainers who were enthusiastic, professional, and experienced were important to the success of staff development programs. 


\section{Summary of Review of the Literature}

The review of the Iiterature presented a summary of relevant studies of the basic characteristics of small firms. Highlighted were the success factors and the causes of small business failure. Of particular significance was the emphasis on the need to develop the human resources in order to ensure the survival and, eventually, the success of small firms.

The critical factors contributing to the success of the small business, which have been identified by a number of researchers, are summarized in Table 5. The majority of the success factors were related to the human resources within the enterprise, a factor over which the small entrepreneur could exercise some control in an effort to achieve success.

As indicated in Table 5, although no single success factor in small businesses was identified, there was strong support for the proposition that financial stability and the quality of the human resources within the small firm had a significant impact on performance and success. Therefore, it is concluded that the availability of the appropriate skills within the small firm has a strong if not direct relationship to success. Relevant programs for training, education, and development should be provided on an on-going basis in order to ensure growth and development. 
Table 5

Factors Critical to Small Business Success

\section{Factors}

Staff development

Flexible control system

Communication Skills

Entrepreneur as final decision-maker
Researchers

(Nadler, 1986) (Olson, 1987) (Nicholson, 1983) (O1son, 1987)

Entrepreneurial behavior

(Ibrahim \& Goodwin, 1986)

Innovation (Brockhaus, 1980)

Creativity (Nicholson, 1983)

Managerial Competence

(Chaganti \& Chaganti, 1983)

Managerial/Interpersonal skills (Ibrahim \& Goodwin, 1986)

Environmental characteristics (Ibrahim \& Goodwin, 1986) Top management involvement (Evans \& Evans, 1988) Skills of key employees (Evans \& Evans, 1988)

Setting of Priorities (Schilit, 1986)

Maintenance of long range orientation (Olson, 1987) Venture \& reserve capital (Chang, 1986) Financial \& strategic planning (Udel, 1978) Internal $\mathrm{R}$ \& $\mathrm{D} /$ Modern equipment (Udel, 1978) Consultancy services (Robinson, 1979) Departmentation (Olson, 1987) Managerial/Employee skills (Thomas, 1988) Entrepreneurial skills (Hope, 1983) 
While the studies of small business development are extensive, all areas of small business operations are still in need of intensive research. A comprehensive theoretical framework is needed to explain the problems of smalI enterprises. It is the intent of this study to investigate the characteristics of one large sector of small enterprise - successful small black-owned firms in Dade County, Florida. 


\section{CHAPTER THREE. METHODOLOGY}

\section{Introduction}

In this chapter, the formulation of the plan and structure of this study is presented. The plan provides a blueprint of the procedures by which the null hypotheses are tested, and the results interpreted. This study examines the characteristics of successful small black-owned firms in Dade County, Florida.

This chapter is presented in three parts. Part One reviews the methodological literature and rationale.

Part Two describes the first phase of the study which is a base data survey of a sample of the target population designed to identify the most and least successful small black-owned businesses. The target population and the selection of the sample from the target population are presented. Also discussed is the rationale for the survey instrument designed to collect the information considered necessary for testing the first null hypothesis formulated in this study, the data collection procedures, and the analysis and interpretation of the data.

Part Three describes the second phase of this study, which involved a guided interview in which the other six null hypotheses were tested. The population and the sample for this phase of the study, the six remaining null hypotheses, the design, construction and field-testing of the interview guide are discussed. Also addressed are the recruitment and 
training of the interviewers, and the data analysis and interpretation.

Part One: Methodological Literature Review and Rationale Review of Methodological Literature

Long et al (1986) define descriptive research as the collection of data in order to answer questions or test hypotheses about the current status of the situation under study. This study involves the collection of data to test the seven null hypotheses derived from the seven research questions. This study utilizes the survey method of descriptive research employing a questionnaire and an interview component to determine the subjects'opinions, attitudes and perceptions about the situation being investigated. The data gathered are quantitatively analysed.

Gay (1987) points out that the descriptive research process is the same as other methods of research. Once a descriptive problem has been defined, related literature reviewed, hypotheses or questions stated, the researcher must give careful thought to the identification of a target population, needed sample size, a data collection strategy, the selection or development of a data collection instrument, the planning and execution of specific procedures of the study, and the analysis procedures.

Gay (1987) further states that since the investigator is often asking questions which have never been posed before, an appropriate instrument must be developed in order to 
acquire the desired information. If instrument development becomes unavoidable, it should be tested and revised before being utilized in the actual study.

Despite the criticisms of survey research, Gay (1987) has argued that descriptive research at its best can generate very valuable data. It involves careful design and execution of the components of the research process, and might describe variables and relationships between variables.

Gay (1987) observes that correlational research is sometimes regarded as a type of descriptive research, because it describes an existing condition. However, the condition it analyses is different from the conditions typically described in self-report or observational studies. As Long et al (1986) state, correlational research involves gathering data to determine the existence of a relationship between two or more variables, and estimating the magnitude of this relationship. Correlational research studies were often classified as relationship studies or prediction studies.

This investigation is also a relationship study designed to examinine the correlation between selected characteristics and success in small black-owned enterprises in Dade County, Florida. Long et al (1986) note that relationship studies, in addition to investigating relationships between variables, often attempt to obtain a better understanding of factors which make up complex constructs such as intelligence, 
self-concept, or success. Relationship studies are also

executed as a preliminary to causal-comparative and experimental studies in order to identify important variables the researcher might want to include in the design of later studies.

\section{Methodological Rationale}

A descriptive and correlational research approach is employed in this study to collect and analyse data and test the seven null hypotheses concerning the relationship between critical factors and success of small black entrepreneurs in Dade County, Florida. The descriptive data required for this study are collected through a questionnaire instrument and guided interviews.

The study also examines the relationship between the key variables and success in small black-owned firms in Dade County, Florida. An interview study is conducted for this purpose. This method is most appropriate as the investigator is interested in determining if there is a relationship between critical factors and success, and if so, the strength of this relationship.

\section{Part Two: The Base Data Survey (Phase One)}

The first phase of this study is focused on the collection and analysis of base data. In this part the target population for the survey is identified, the sample size and selection determined, the data collection instrument selected, and the data collection procedures outlined. The 
methods of data analysis are discussed in light of the null hypotheses developed above.

\section{Target Population}

The population for the first phase of this study is the small black entrepreneurs in Dade County, Florida, who employed at least one full-time employee. Thomas (1988) reports that, according to a Small Business Administration study, approximately 3,885 small black-owned firms were operating in Dade County, Florida in 1982. The study indicates that $20 \%$ of black-owned firms were corporations, $8.72 \%$ partnerships, and $71.28 \%$ were sole proprietorships. However, the study by Thomas (1988) reveals a very different pattern. A total of $70.9 \%$ were corporations, $23.6 \%$ were sole proprietorships, and 5.5\% partnerships. The survey data base developed by Thomas (1988) is mainly procured from minority vendor lists of state and local governments, as well as other organizations. Thomas notes that black businesses seeking contracts from governments and/or large private sector organizations are more likely to be formed as corporations.

In 1987 there were 961 small black-owned enterprises in Dade County which had at least one employee. Fully 86 percent of the County's black-owned businesses in 1987 were owner-operated (Metro-Dade County Planning Department, 1991). Based on these data, the number of black-owned firms in Dade County, Florida, in 1987 is computed at approximately 6,800. 


\section{Total Sample and Selection}

The sample for the first phase of this study consisted of 580 small entrepreneurs (approximately $60 \%$ of the 961 small black entrepreneurs in Dade County, Florida, who engaged at least one full-time employee). Gay (1987) states that for a descriptive study, a sample of $10 \%$ is considered minimally satisfactory. A random sampling technique was used to derive a representative sample to reflect the basic characteristics of black entrepreneurs in Dade County, Florida. The sample was selected from the list of small black entrepreneurs prepared by the Metro-Dade Office of Black Affairs. A table of random numbers was employed in the selection of the sample, and an arbitrary starting point identified. The size of the sample (580) and the method of selection (random sampling) ensured its representativeness and independence of units. This process has facilitated the generalizability of the results to the target population.

\section{Instrumentation selection}

For the first phase of this study, the data collection instrument selected was a mailed self-administered questionnaire. The members of the sample were widely dispersed throughout Dade County, and consequently personal interviews would have been difficult to inplement. In addition, a current telephone list of the black entrepreneurs in Dade County was unavailable. In contrast, it was possible to compile a list of the postal addresses of small black 
entrepreneurs in Dade County, Florida, through the cooperation of a number of agencies such as the Bureau of Black Affairs of Dade County, the SBA, the SBDC, and the Miami/Fort Lauderdale Minority Small Business Development Center. For the base data survey, the list developed by the Bureau of Black Affairs of Dade County, Florida, was used as it was the most comprehensive and relevant.

The NuIl Hypothesis to be Tested in Phase one

The basis of the study is the seven null hypotheses outlined in Chapter One. The first null hypothesis, which is focused in this Chapter, is: The general characteristics are the same for all successful small black-owned firms.

\section{Data collection Procedures for Phase One}

The strategy employed for the first phase of this study was a survey of a random sample of the target population. This phase generated base data through a mailed questionnaire that described the subjects, and identified how many were most successful, less successful, and least successful.

The research method, target population, sample size and selection, and the data collection instrument for the first phase of the study were discussed above. The other steps in this phase of the investigation were the following: Construction of the Questionnaire

The questionnaire developed for the study was neat, attractive, and easily understood. All the items were directly related to the objectives of the study, and were 
structured and based on categorical and numneric variables. Each question was concerned with a single topic, and was worded with clarity. Leading questions were avoided in constructing the questionnaire, and appropriate directions for its completion were provided. The complete questionnaire is included in the Appendix (Appendix D). Preparation of the Cover Letter

Each mailed questionnaire was accompanied by a cover letter explaining what the respondent was asked to do. The letter was structured so as to motivate the respondent to comply with the request. The letter was brief, neat, and was addressed specifically to each subject, explaning the purpose, importance, and significance of the study. A commitment was given to the firms concerning the sharing of the results of the study upon its completion. A copy of the letter is included in the Appendix (Appendix B).

The Director of the Miami/ Fort Lauderdale Minority Business Development Center, to which many of the small black entrepreneurs in Dade County, Florida, were affiliated, provided a letter of endorsement of the study. It was expected that the enclosure of the letter would generate a higher level of response in the base data survey. A copy of this letter is included in the Appendix (Appendix C).

A definite deadine date by which the completed questionnaire should be returned was given. Each subject was requested to reply within two weeks. Finally, a stamped, 
addressed, return envelope was enclosed with each questionnaire in order to encourage each subject to reply. The questionnaire was field-tested to identify any defects in the instrument as well as any areas requiring refinement. Field-testing the Questionnaire

Three menbers of the faculty at Florida International University (two from the college of Education, and one from the Department of Statistics) and the Director of the Miami/Fort Lauderdale Minority Business Development Center were asked to complete and critique the questionnaire.

After revision, the instrument and the cover letter were then forwarded to a small sample $(\mathrm{N}=10)$ of the target population. The subjects were encouraged to comment on the directions, recording procedures, and the specific items. In addition, the data tabulation and analysis procedures were tried with the pilot project data. The result of the pilot project was a revised instrument ready to be sent to the total randomly selected sample.

Determination of the Response Rate

The target response rate for the first phase of the study $(\mathrm{N}=580)$ was a minimum of $70 \%$, as suggested by Gay (1987) for descriptive studies. A major effort was made to achieve the highest response rate. The questionnaire was made to look professional, personalized, and attractive as those features would tend to have a positive effect on the response rate (Linsky, 1975 ). 


\section{Follow-up Activities}

Fourteen days after the initial mailing, a reminder card was sent to all the nonrespondents, emphasizing the importance of the study, and the need for a high rate of response. About ten days after the mailing of the postcard, another letter and questionnaire were sent to the remaining nonrespondents again stressing the significance of a high rate of return. If the rate was still unsatisfactory, the nonrespondents would then be contacted by telephone. If telephone numbers were not available and personal calls inappropriate, an additional persuasion letter, night telegraph letter, or other follow-up procedures that seemed appropriate would be employed.

\section{Treatment of Bias}

The effect of nonresponse on survey estimates depended on the percentage not responding, and the extent to which those not responding were biased - that is, systematically different from the whole population. If the majority in the sample provided data, sample estimates were still reliable even if the respondents had distinct characteristics (Fowler, $1988)$.

In the mail survey, bias due to nonresponse was studied by comparing those who responded immediately to those who did so after follow-up procedures were instituted. Fowler (1988) states that one important generalization that holds for most mail surveys is that individuals who have a distinct interest 
in the theme or in the research itself are likely to return mail questionnaires more promptly than people who are less interested. This means that mail surveys with low response rates are usually biased significantly in ways that are directly related to the objectives of the research (Donald, 1960).

Fowler (1988) reports that early returns in mail surveys are biased. Data resulting from returns of $20 \%$ or $30 \%$, which are typical of mail surveys that are not followed up effectively, usually do not represent the sampled population. Another bias in mail surveys is that people with high levels of education often return questionnaires more readily than those with less education (Fowler, 1988). Therefore, a mail survey of any variable related to education would likely produce biased estimates unless steps are taken to realize a high response rate.

\section{Data Analysis and Interpretation}

After the data collection process, a permanent data file was created consisting of the information to be analysed. As Greenberg (1987) notes, it is important that the file be accurate, reflecting the actual data gathered. If the information in the data file does not truly represent the data collected, then the findings of the study would be erroneous despite the meticulous way the other aspects of the investigation are conducted. That is particularly the problem when data are obtained by means of a mailed questionnaire. 
To ensure sound results in the study, the responses were coded, as Greenberg (1987) suggests, in the instrument itself to facilitate conversion to computer entry. A coding system was used to determine what number to enter for each response. In addition, coding sheets were utilized to transfer data from the questionnaire to the computer. All of the data were scrutinized to verify the accuracy of the computer entries.

Frequency counts and percentages were utilized to describe the data from the base data survey. From these data two groups were selected for the second phase of the study. One group of most successful and another of least successful small black entrepreneurs were randomly chosen. The Chi-Square test was employed to assess the relationship between the two groups on the categorical variables. T-tests were used to compare the group of successful and the group of least successful small black entrepreneurs on the numeric variables.

Part Three: The Interview Study (Phase Two)

The second phase of this study involved a guided interview. The interview was designed to collect data in order to test the six remaining null hypotheses Iisted on the next page. To be described in this part of the chapter are the target population and total sample of the second phase, the null hypotheses, the selection of the data collection instrument, the construction and field-testing of the 
interview guide, the recruitment and training of the interviewers, and the techniques of data analysis and interpretation.

\section{Population and Total Sample for Phase Two}

The target population for the second phase of this study was composed of the most successful and least successful small black entrepreneurs in Dade County, categorized on the basis of profit in Phase one. The random sampling method involving a table of random numbers was used to select a sample consisting of two equal-sized groups - one group of twenty most successful and another group of twenty least successful small black entrepreneurs.

\section{Nul1 Hypotheses to be Tested in Phase Two}

Six of the null hypotheses introduced in chapter one were analysed in this phase of the study. The first null hypothesis was analysed in Phase one. The remaining six null hypotheses are:

2. The critical factors essential for success are identical in all small black-owned businesses.

3. There is no relationship between the amount of selected critical factors and success in small black-owned firms.

4. Staff development is not one of the determinants of success in small black-owned firms.

5. Small black entrepreneurs are not aware of the role of staff development in the success of their firms.

6. The leadership styles of small black entrepreneurs do 
not affect success in their firms.

7. There is no relationship between HRD skills and success in small black-owned firms.

\section{Process Selection}

The process employed in the data collection to test the above null hypotheses was a guided personal interview. This strategy permitted the researcher to obtain detailed data not possible with a mailed or telephone questionnaire. When responses were vague, the interviewer could secure more accurate answers by posing additional probing questions. Small entrepreneurs might be more confident to give verbal responses to some sensitive questions rather than written answers.

\section{Construction of the Interview Guide}

A written interview guide was prepared to indicate which questions were to be posed and in what order, and what additional probing might be allowed. Each question in the interview was related to a definite study objective. The questions were structured with the interviewees required to select from alternative answers. That approach facilitated the analysis of the data. However, the interview itself was semi-structured, i.e. structured questions were followed by clarifying open-ended questions. The open-ended questions facilitated explanation and comprehension of the responses to the structured questions. Consequently, there was a combination of objectivity and depth, facilitating the 
tabulation and analysis of the data. The complete interview guide is included in the Appendix (Appendix E).

\section{Recording the Responses}

Responses made during the interview were tape-recorded subject to the permission of the respondent. In that way the interview was expedited in that time was not lost in writing down information. Responses were tape-recorded exactly as given, a method that was both objective and efficient. In the case of sensitive questions, full clarifications were provided before their presentation, and assurances given as to the confidentiality of the information.

\section{Field-testing the Interview Guide}

The interview guide, interview procedures, and the analysis procedures were field-tested before the commencement of the main study. A small sample of $N=10$ was selected from the population identified for this study. Feedback from the pilot study was utilized to revise questions which were vague and did not generate the desired information. The pilot study also indicated if the data collected could be quantified and analysed in the manner planned.

\section{Recruitment and Training of Interviewers}

Two interviewers were engaged for the task of data collection. They were trained in order to ensure their efficiency and effectiveness. The content of training included both general information concerning surveys, and information vital to this study. The general topics included 
in the training program were:

1. Procedures for contacting respondents and introducing the study.

2. The conventions that were used in the wording of the questionnaire so that the interviewers could ask the questions in a consistent and standardized way.

3. Procedures for probing inadequate responses in a nondirective way.

4. Procedures for recording answers to open-ended and closed questions.

5. Rules and guidelines for handling the interpersonal aspects of the interviews in a nonbiased manner.

The interviewers were provided with the following background information on this study:

1. The specific purposes of the study, including the general research goals, and the anticipated uses of the findings of the research. That information was vital to providing respondents with appropriate answers to questions and helping to enIist their support.

2. The specific approach that was used for sampling, to provide a basis for answering respondents'questions.

3. Details regarding the purposes of specific questions.

4. The steps to be taken concerning confidentiality, and appropriate assurances to be given to respondents. 
Data Analysis and Interpretation

After data collection, a permanent data file was prepared, composed of the data to be processed. The responses in the interviews were coded in preparation for entry into the computer. A coding scheme was utilized to decide what number to enter for each response. Coding sheets were used to transfer data from the interview schedules to the computer. All the computer entries were verified by an analysis of all the data.

Descriptive statistical techniques were used to analyse the data from the interview schedules. Frequency counts and percentages were computed for that purpose.

Crosstabulation and the Chi-Square test were employed to analyse the relationship between critical factors and success in small black-owned enterprises in Dade County. The t-test was utilized to compare the two groups of most successful and least successful small black entrepreneurs on the six null hypotheses posed above. The t-test was appropriate as each group was composed of only twenty subjects, with the data being continuous (Fink, A., Kosecoff, J., 1985). 
CHAPTER FOUR: PRESENTATION AND ANALYSIS OF DATA

Introduction

The focus of this chapter is on the presentation and analysis of the data from both the base data survey and the guided interviews in order to examine the characteristics of the successful small black-owned enterprises in Dade County, Florida. The first section describes the pilot study. The second section presents the data collection procedures for Phase one, the treatment of bias, summary descriptive data from the base data survey, and the testing of the first null hypothesis. Finally, the third section provides summary descriptive data from the guided interviews, and the testing of the remaining six null hypotheses.

\section{Pilot study}

The measurement instrument and selected statistics were tested in a pilot study of a small randomly selected sample of small black-owned firms in Dade County, Florida. The questionnaire designed for Phase one of this study was mailed to ten randomly selected subjects. As only three were returned within two weeks of the mailing date, a reminder card was sent to the nonrespondents, underscoring the importance of the pilot study and the need for a high rate of response. Within ten days of the dispatch of the postcard, two more completed questionnaires were received. The five nonrespondents were contacted by telephone, and were encouraged to respond to, and to comment on the design and 
content of, the questionnaire and the cover letter. Two more questionnaires were received within two weeks of the telephone contact. The final response rate for the questionnaire component of the pilot study was $70 \%$, which is considered satisfactory for descriptive studies (Gay, 1987).

A data file was created for the questionnaire segment of the pilot study. Frequency counts and percentages were calculated to describe the data. The Chi-square test and the t-test were applied in the analysis of the data collected.

From the questionnaire component of the pilot study, a few revisions in the instrument and the cover letter were made, e.g. a simpler vocabulary and more specific examples. The pilot study, however, did indicate that the subjects were able to answer the questions; and the statistical measures selected for the questionnaire study were appropriate for the data collected.

Another sample of ten subjects was randomly selected from the target population to field-test the interview guide, the instrument used for the second phase of the study. The ten interviews were conducted by the researcher. The subjects were cooperative, and responded well to the questions.

Certain technical terms were explained as they were difficult for the interviewees. They were "internal $R \& D "$ "group process," "deparmentation" "learner outcomes", and "instructional strategies".

A data file was made of the data gathered from the pilot 
interview study. The statistical measures for the second phase of this study were employed to evaluate their use in this study. Based on the pilot interview study, several revisions of the interview guide were made, e.g. a simpler vocabulary and the deletion of unnecessary words. In general, however, the results did verify that the interviewees were able to verbally answer the questions with appropriate explanations and clarifications by the interviewer.

\section{Base Data Survey (Phase One)}

For describing and drawing inferences about the characteristics of small black entrepreneurs in Dade County, Florida, a sample of 580 (60\%) small black entrepreneurs was randomly selected from the target population $(\mathrm{N}=961)$. A sample of 60 percent was selected in order to ensure its representativeness of the target population. The sample of selected entrepreneurs is herein referred to in this study as the "sample".

\section{Data Collection Procedures}

A questionnaire, accompanied by a cover letter and a letter of endorsement from the Director of the Miami/Fort Lauderdale Minority Business Development Center, was mailed to each subject in the sample $(N=580)$. Approximately $25 \%$ (143) of the subjects responded within fourteen days of the initial mailing. Two percent (12) of the questionnaires were returned undelivered. Telephone contact was made with the nonrespondents in order to verify the names of the contact 
persons, telephone numbers and addresses. In eighteen cases the mailing list was revised to reflect relevant changes. The eighteen firms were once more sent questionnaires. In addition, reminder cards were mailed to the remaining nonrespondents, stressing again the value of the study, and the need for a high response rate.

Within fourteen days of the mailing of the reminder cards, about 25\% (144) of the subjects responded. Telephone contact was made with each of the remaining 281 nonrespondents, and within two weeks 47 questionnaires were returned. Finally, the 234 nonrespondents were again contacted by telephone, and 19 more responses were received within fourteen days. The final number of responses received was 353 ( $37 \%$ of the target population of 961).

\section{Treatment of Bias}

Follow-up measures were adopted in order to generate a high response rate, thereby minimizing any effect of bias on the survey estimates. Bias due to nonresponse was studied by comparing those who responded immediately to those who did so only after follow-up activities were instituted. The two groups of respondents were compared on the variables "interest in the study", "level of education", and "number of years in business". Ten respondents from each group were selected and interviewed.

Table 6 indicates the results of the comparison. Both the early and the late respondents were equally interested in 
the study. The average years of public education completed by both groups were nearly similar. The average number of years in business was close for both groups.

Table 6

Comparison of Early and Late Respondents to the Phase One Survey $(N \equiv 20)$

\begin{tabular}{|c|c|c|}
\hline & Years of & \\
\hline Interest in & Public & Years in \\
\hline \multirow[t]{2}{*}{ Study } & Education & Business \\
\hline & (Average) & (Average) \\
\hline 10 & 11.5 & 9.0 \\
\hline 10 & 11.2 & 8.5 \\
\hline
\end{tabular}

Summary Descriptive Data of Base Data Survey

In this section of the study the data for the entire sample in the phase one base data survey are summarized. Frequency counts and percentages were calculated to describe the data collected. The first research question, which forms the basis of this part of the study, is: What are the general characteristics of small black-owned firms?

The characteristics highlighted are: period of time in present business, form of business organization, major business activities, number of full-time employees, number of part-time employees, and number of years a net profit was earned in the period 1985 to 1989. 
Table 7 shows the relative periods of time the sampled entrepreneurs were in business. About half ( $47 \%$ ) of the small entrepreneurs were in business for five to seven years, a little over one-tenth $(12.5 \%)$ for seven to ten years, and approximately two-fifths $(40.5 \%)$ for more than ten years. The mortality rate among small enterprises is usually very high. Steiner and Solem (1988) reported that about 70 percent of small firms failed within the first four years.

Table 7

Periods of Time Black-owned Firms in Present Business $(N \equiv 353)$

\section{Frequency Percent}

$$
5-7 \text { Years }
$$

166

47.0

7 - 10 years

44

12.5

$>10$ years
40.5

Total 353 100.0

The different forms of business organization identified in the sample are indicated in Table 8. Approximately half (50.4\%) of the small enterprises were set up as sole proprietorships, nearly two-fifths (38\%) as corporations, and over one-tenth $(11.6 \%)$ as partnerships. These data are consistent with the trend in the SBA data base for 1987 (Bureau of the Census, 1990), which revealed that most of the black-owned firms in Dade county were sole proprietorships 
(71.28\%), followed by those organized as corporations (20\%), with the minority being partnerships ( $8.72 \%)$.

Table 8

Forms of Business organization in Black-owned Firms (N $\equiv 353)$

Frequency

Sole Proprietorships

Corporations

Partnerships
178

134

$\underline{41}$

$\underline{353}$
Percent

$50 \cdot 4$

38.0

11.6

100.0

The major business activities of the sampled firms are presented in Table 9. Over three-fourths (76.8\%) of the firms were engaged in the retail trades (39.4\%) and services $(37.4 \%)$. Professionals accounted for less than one-tenth $(7.4 \%)$ of those surveyed. It is apparent that relatively few of the small black entrepreneurs were engaged in construction (4.5\%), manufacturing (3.7\%), financial services (3.4\%), transportation (2\%), wholesale $(1.7 \%)$, and agriculture $(.6 \%)$. The major business activities of the small black-owned firms were the retail trades, services, the construction trades, and the professions. These findings are basically consistent with those of the Metro-Dade Office of Black Affairs (1987). The latter report states that small black-owned firms in Dade County, Florida, are mainly concentrated in a variety of service industries such as the retail trades and services. 
Table 9

Major Business Activities of Black-owned Firms (N $\equiv 353$ )

Frequency

Retail

Services

Professional

construction

Manufacturing

Financial

Transportation

Wholesale

Agriculture
139

132

26

16

13

12

7

6

2
Percent

39.4

37.4

7.4

$4 \cdot 5$

3.7

$3 \cdot 4$

2.0

1.7

.6

Total

$\underline{353}$

100.0

Table 10 provides some interesting information on ful1-time employees in the sampled firms. Nearly two-thirds ( $59.2 \%$ ) of the firms employed between one and two full-time workers. Less than three percent (2.9\%) of the sampled firms had 16 or more full-time employees each. These findings were expected as the small black-owned firms in Dade County, Florida, were usually small in size, and were largely owner-operated with no employees (Metro-Dade County Planning Department, 1986). Besides, only 14 percent of small black firms in Dade County had one or more full-time employees (Metro-Dade County Planning Department, 1991). 
Table 10

Full-time Employees in Black-owned Firms (N $\equiv \underline{\text { 353) }}$

$\begin{array}{lcc}\text { No. } f \text { Employees } & \text { Frequency } & \text { Percent } \\ 1 & 107 & 30.3 \\ 2 & 102 & 28.9 \\ 3-4 & 80 & 22.6 \\ 5-9 & 43 & 12.1 \\ 10-15 & 11 & 3.2 \\ 16 \text { or more } & \underline{10} & \underline{2.9} \\ & \underline{353} & \underline{100.0}\end{array}$

Part-time employees are sometimes needed whenever there is a significant upturn in the volume of business. The number of part-time workers in the firms is presented in Table 11. Table 11

Part-time Emplovees in Black-owned Firms (N $\equiv 353$ )

No. of Employees

0

1

2

$3-4$

$5-8$

8 or more
Frequency

199

76

34

29

10

5
Percent

56.4

21.5

9.6

8.2

2.8

1.2 
Table 11 indicates that over half (56.4\%) of the sampled firms had no part-time employees. About one percent (1.2\%) of the firms had eight or more part-time workers. Part-time employees are apparently not prevalent among small black firms. The entrepreneur often has to hire full-time workers due to the multiplicity of details requiring attention. Like all businesses, the main objective of the small black-owned firm is to realize a satisfactory annual net profit. Net profit is the surplus of total revenue over total expenses (including overheads). The number of years a net profit was made by the sampled firms is shown in Table 12. Table 12

Number of Years Net Profit Earned in Period 1985-89 by Black-owned Firms $(N \equiv$ 353)

No. of years

1

2

3

4

5

Total
Frequency

40

44

64

45

160

353
Percent

11.3

12.5

18.1

12.7

45.3

100.0

Table 12 shows that during the period 1985 to 1989, almost half (45.3\%) of the sampled firms were most successful as they realized a net profit every year. Almost one-third 
(30.8\%) were less successful, generating a net profit for three to four years during the period. Finally, almost a quarter of the firms (23.8\%) were least successful as they earned a net profit for two years or less. The latter were marginal firms which could be forced into bankruptcy by the slightest downturn in the general level of business.

Net profit made by the sampled firms in 1989 is outlined in Table 13. In 1989 approximately one-fifth (20.1\%) of the firms did not make a net profit. Almost two-thirds (63.2\%) earned a net profit less than $\$ 50,000$ for the year. Slightly more than one-tenth (13.6\%) of the firms realized a net profit of $\$ 50,000$ to $\$ 150,000$ in 1989 . In fact, almost all (99.7\%) of the firms made a net profit less than $\$ 300,000$, with only one earning a net profit of $\$ 400,000$ to $\$ 450,000$. Table 13

Net Profit Earned in Year Ending December 31, 1989, by Black-owned Firms (N)

\section{Frequency}

None

$<\$ 50,000$

$\$ 50,000-\$ 150,000$

$\$ 150,000-\$ 200,000$

$\$ 250,000-\$ 300,000$

$\$ 400,000-\$ 450,000$
71

223

48

8

2

1

Total
Percent 20.1 63.2 13.6 2.3 .6 .3 
In summary, as shown in Tables 7 to 13 , almost half $(47.0 \%)$ of the sampled firms were in their present business for five to seven years, and approximately two-fifths (40.5\%) for more than ten years. The principal form of business organization among the sampled firms was the sole proprietorship. The majority were in the retail trade $(39.4 \%)$ and services $(37.4 \%)$. Nearly two-thirds $(59.2 \%)$ of the black-owned firms engaged only one to two full-time employees; and over a half $(56.4 \%$ ) had no part-time workers. Almost half (45.3\%) of the firms made a net profit every year in the period 1985 to 1989. Nearly two-thirds of the firms $(63.2 \%)$ realized a net profit of less than $\$ 50,000$ in 1989 . Having described the respondents in the base data survey, the first of the seven null hypotheses is tested in the next section of this study.

\section{Testing of the First Null Hypothesis}

The first null hypothesis was tested in Phase One of this study. The first null hypothesis is: The general characteristics are the same for all small black-owned firms.

The Chi-Square measure of relationship was used to test the relationship between the charactertistics and success in the most successful and the least successful small black firms. The characteristics examined were: period of time in present business, form of business organization, major business activities, net profit earned in 1989, number of full-time employees, number of part-time employees, and 
number of years net profit earned in the period 1985 to 1989. Table 14 presents the periods of time the sampled firms were in their present business. Almost two-thirds (61\%) of those in business for 5 to 7 years were least successful. However, that proportion fell to over one-tenth (16\%) for those in business for more than ten years. More than four-fifths ( $86 \%$ ) of the firms in business for more than ten years were most successful. As the observed significance level of $.000<p=.01$, the relationship between number of years in business and success is significant. The length of time in business is likely to affect the firm's success. Table 14

Comparison of Present Business and Success in Black-owned Firms $(\mathbb{N} \equiv \underline{244)}$

\section{Success}

Most

Least

Present Business Successful Successful

$5-7$ yrs

$7-10$ yrs

10 yrs

$\underline{\text { Total } \quad \underline{160}} \underline{84}$

$40(39 \%)$

$26(87 \%)$

$94(86 \%)$

Total $\underline{160} \quad \underline{84}$

$63(61 \%)$

$4(13 \%)$

$16(14 \%)$
Chi-Square
Value
DF
Significance
Pearson
58.00316
2
.000 
form of business organization, and success is presented in Table 15. Whereas there was a slight difference in the percentages of most successful and least successful firms organized as sole proprietorships, more than two-fifths (42\%) of the most successful firms were set up as corporations, in comparison to less than one-third (31\%) of the least successful. In addition, 18 percent of the least successful small black-owned firms were organized as partnerships, compared to nine percent of the most successful. The relationship between form of business organization and success is not considered significant as the observed significance level of $.086>p=.05$.

Table 15

Comparison of Form of Business Organization and Success in Black-owned Firms $(\mathrm{N} \equiv 244)$

\section{$\underline{\text { Success }}$}

Most

Least

Form of Business organization Successful Successful Sole Proprietors 78 (49\%) 43 (51\%)

Partnerships 15 (9\%) 15 (18\%) Corporations $67(42 \%)$ $26(31 \%)$

Total 160

84

Chi-Square Value

DF

Significance Pearson 5.01350

2 .086 
The comparison between the third characteristic, major business activities, and success is presented in Table 16. The sample in this analysis is $\mathrm{N}=219$, as less important business activities were excluded (those activities engaged 134 of the 353 sampled firms for Phase one of this study). The business activities excluded were: financial services, manufacturing, transportation and wholesale.

Table 16

Comparison of Major Business Activities and success in Black-owned Firms $(N \equiv 219)$

\title{
Success
}

Most

Major Business Activities

Construction

Retail

Services

Professional

Total

Value

13.31342
Pearson
Chi-Square
Successful

13 (9\%)

50 (36\%)

59 (42\%)

$18(13 \%)$

140

DF

3
Least

Successful

$2(2 \%)$

45 (57\%)

29 (37\%)

3 $(4 \%)$

\author{
.
}


(57\%) of the least successful firms were in retail trades, less than two-fifths (36\%) of the most successful were in that subsector. The two major business activities of both the most and least successful firms were the retail trades and services. As the observed significance level of $.004<\mathrm{p}=$ .01 , the relationship between major business activities and success is significant.

The relationship between the amount of net profit made in 1989 and success is shown in Table 17.

Table 17

Comparison of Net Profit Earned in 1989 and Success in Black-owned Firms $(N \equiv 244)$

\section{Success}

Most

Least

Net Profit

None

$<\$ 50,000$

$\$ 50,000-\$ 150,000$

$>\$ 150,000$

Chi-Square

Pearson
Total 160

Successful

1 (1\%)

$120(75 \%)$

33 (21\%)

$6 \quad(3 \%)$

Value

71.27405
DF

3
Successful

32 (38\%)

47 (56\%)

3 (4\%)

2 (2\%)

84

Significance

.000

As presented in Table 17, whereas nearly two-fifths (38\%) of the least successful firms did not generate a net 
profit in 1989, only one percent of the most successful firms failed to do so. Three-quarters of the most successful small black entrepreneurs made a net profit less than $\$ 50,000$ in 1989, compared to less than three-fifths (56\%) of the least successful firms. In addition, more than one-fifth (21\%) of the most successful firms realized a net profit of $\$ 50,000$ to $\$ 150,000$ in 1989 , compared to only four percent of the least successful. As the observed significance level of .000 $<p$ $=.01$, the relationship between net profit in 1989 and success is significant.

The $t$-test was used to compare the most and least successful respondents on the numeric variables - number of full-time employees, number of part-time employees, and number of years a net profit was earned in the period 1985 to 1989. The t-test analysis of the differences between the two groups on the above variables is indicated in Table 18.

As presented in Table 18, the most successful firms had an average number of full-time employees of 4.78 , whereas the least successful had 2.75 full-time employees. As the observed significance level of $.048<p=.05$, the difference between the the most and least successful small black-owned firms on the variable "number of full-time employees" is significant. Therefore, the null hypothesis is rejected. 
Table 18

t-test of Differences Between the Most and Least Successful Black-owned Firms on the Variables "Full-time Employees", "Part-time Employees", and "Number of Years Net Profit Earned in the Period 1985-1989".

\section{Most Least \\ Successful successful \\ $(\mathbb{N} \equiv \underline{160)} \quad(N \equiv \underline{84)}$}

Mean(std) Mean(std) t-statistic p-value

Ful1-time Employees 4.78 (9.1) 2.75 (2.7) $\quad-1.99 \quad 048$

Part-time Employees 1.44 (4.0) 1.32 (5.0) - .20 .838

No. of Years Net

Profit Earned $\quad 5.00(0.0) 1.52(.50)-87.68 \quad .000$

In regards to the variable "number of part-time employees", the mean for the most successful black-owned firms is 1.44, and that for the least successful is 1.32. As the observed significance level of $.838>p=.05$, the difference between the most and least successful black-owned firms on the variable "part-time employees" is not significant. Thus the null hypothesis is not rejected.

In respect to the variable "number of years net profit earned", the mean number of years the most successful small black entrepreneurs made a net profit is 5.00 , and that for the least successful is 1.52. As the observed significance 
level $.000<p=.01$, the difference between the two groups on the variable "number of years a net profit was earned" is significant. Therefore, the null hypothesis is rejected. The most successful small black-owned firms made a net profit for more years in the period 1985 to 1989 compared to the least successful firms.

In summary, the first null hypothesis was tested in this section of the study. The most and least successful small black entrepreneurs were compared on certain categorical variables, viz. period of time in present business, form of business organization, major business activities, and net profit earned in 1989. The relationship between these categorical variables and success was tested. The most and least successful small black-owned firms were also compared on certain numeric variables -number of full-time employees, number of part-time employees, and the number of years a net profit was earned in the period 1985 to 1989.

The relationship between the following variables and success was found to be significant: number of years in present business, major business activities, and net profit earned (in 1989). No significant relationship was determined between form of business organization and success. The differences between the most and least successful black-owned firms on the following variables were significant: number of full-time employees, number of years a net profit was earned. No significant difference between the two groups was 
determined in respect to "number of part-time employees".

As all the characteristics are not the same for both the most successful and the least successful small black-owned firms, the first null hypothesis is rejected.

\section{Interview Study (Phase Two)}

In this section are described the data pertaining to the total sample for Phase Two of this study. Frequency counts and percentages are used to describe the data collected. This phase also involves the testing of the remaining six null hypotheses. The t-test analysis is used to test the differences between the two groups of black-owned firms on the numeric variables, and the Chi-square to assess the relationship between the categorical variables and success.

Summary Descriptive Data of Interview study

The first research question, which was posed in Phase one of this study, was: What are the general characteristics of small black-owned firms? The six remaining research questions constitute the basis of the interview study (Phase Two). The data presented in this section are organized around the six remaining research questions.

Second Research Question

The second research question is: What critical factors are essential for success in small black-owned firms? The data related to the second research question in this study are summarized in Tables 19 through 33.

The critical factors examined in the second research 
question were: staff development, flexible informal control system, close unstructured communication system, entrepreneur as final decision-maker, entrepreneurial behavior, innovation, creativity, managerial competence, managerial skills, interpersonal skills, environmental characteristics, the involvement of top management in the operations of the firm, skills of key employees, the setting of priorities, and the maintenance of a long-range orientation.

Table 19 illustrates how the sampled firms evaluated staff development - training, education and development - as a success factor.

Table 19

Staff Development as a Success Factor in Black-owned Firms $\underline{(N} \equiv \underline{40)}$

Training Education Development Freq. Per. Freq. Per. Freq. Per.

$\begin{array}{lrrrrrr}\text { Not at all essential } & 0 & 0.0 & 0 & 0.0 & 1 & 2.5 \\ \text { Slightly essential } & 1 & 2.5 & 8 & 20.0 & 3 & 7.5 \\ \text { Essential } & 7 & 17.5 & 12 & 30.0 & 9 & 22.5 \\ \text { Very essential } & 16 & 40.0 & 10 & 25.0 & 14 & 35.0 \\ \text { Most essential } & \underline{16} & \underline{40.0} & \underline{10} & \underline{25.0} & \underline{13} & \underline{32.5} \\ \quad \underline{40 t a l} & \underline{40} & \underline{100.0} & \underline{40} & \underline{100.0} & \underline{40} & \underline{100.0}\end{array}$

Training involves providing the employee with the skills required to perform the present job. Table 19 
shows that 80 percent of the subjects considered training as very or most essential as a success factor in black-owned businesses. Less than three percent (2.5\%) regarded training as a slightly significant success factor.

Education involves providing the employee with the requisite skills to perform a specific job within the firm in the near future. As presented in Table 19, whereas one-fifth of the sample considered education as a slightly essential success factor, half regarded it as very or most essential to the successful operation of a small black-owned business. This assessment is particularly noteworthy when it is recalled that small entrepreneurs lack control over two important ingredients for success - financial resources and physical resources. The quality of the human resources in the firm needs emphasis; hence, the significance of education and training.

Development is the process of imparting to the employee the knowledge and skills to enable him to grow with the firm over time. As indicated in Table 19, one-tenth of the sampled firms viewed development as not or slightly essential as a success factor in small black-owned firms; while more than two-thirds $(67.5 \%)$ considered the factor very or most essential. If the small entrepreneur realizes the value of development, he is more 1 ikely to be concerned with the need for staff development when promoting the growth of the firm. Control is required for the timely detection and 
remediation of deviations from plans within the firm. The sampled firms'evaluation of a flexible, informal control system in the successful management of small black-owned enterprises is illustrated in Table 20. Whereas one-tenth of the sampled firms regarded a flexible, informal control system as a slightly or not essential success factor, more than two-thirds (67.5\%) viewed it as very or most essential. An effective control system ensures that activities are efficiently organized and coordinated in the firm. Whenever the contrl system is flexible and informal, the employees are more likely to approach management with suggestions for improvement without inhibition.

Table 20

A Flexible Informal Control system as a success Factor in Black-owned Firms $(\mathbf{N} \equiv 40)$

Frequency

Not at all essential

Slightly essential

Essential

Very essential

Most essential
1

3

9

14

13

40
Percent

2.5

7.5

22.5

35.0

$32 \cdot 5$

100.0

Tota1

1

The evaluation of a close unstructured communication system as a success factor is shown in Table 21. 
Table 21

Close Unstructured Communication system as a Success Factor in Black-owned Firms $(N \equiv \underline{40)}$

Frequency

Not at all essential

Slightly essential

Essential

Very essential

Most essential
2

6

8

Total
12

12

40
Percent

$$
5.0
$$

15.0

20.0

30.0

30.9

100.0

Table 21 indicates that one-fifth of the sampled firms viewed a close, unstructured communication system as not or slightly essential to the success of a small black-owned enterprise. In contrast, over three-fifths (60.9\%) considered this factor as very or most essential to the success of small black-owned businesses. An effective communication system is likely to allow everyone to know the plans, policies and procedures relevant for success.

The location and implementation of the decision-making function are vital to the efficient performance of the firm. The assessment of the entrepreneur as final decision-maker in the success of small black-owned enterprises is shown in Table 22 . 
Table 22

Entrepreneur as Final Decision-maker as a success Factor in Black-owned Firms $(N \equiv \underline{40)}$

Frequency

Not at all essential

Slightly essential

Essential

Very essential

Most essential
0

3

8

11

18

40
Percent

0.0

$7 \cdot 5$

20.0

27.5

45.0

100.0

As presented in Table 22, whereas nearly three-tenths (27.5\%) of the small black-owned firms considered the role of the entrepreneur as final decision-maker slightly essential. or essential, nearly half $(45.0 \%)$ regarded this factor as most essential for success. At times rapid decisions are required within the firm to ensure survival in the modern competitive economy. In such situations, it is likely that the entrepreneur is the most suitable person to make important business decisions.

Table 23 illustrates the sampled firms" assessment of entrepreneurial behavior as a success factor. Whereas a quarter of the sampled firms regarded entrepreneurial behavior as slightly essential as a success factor, nearly two-thirds $(65.0 \%)$ viewed this factor as very or most 
essential. Entrepreneurial behavior often sets the tone of the firm, and influences the leadership styles of senior personne1.

Table 23

Entrepreneurial Behavior as a Success Factor in Black-owned Firms $(\mathbb{N} \equiv 40)$

\section{Frequency}

Not at all essential

slightly essential

Essential

Very essential

Most essential
0

10

4

10

16

40
Percent

$$
0.0
$$

25.0

10.0

25.0

40.0

100.0

Tota1

잉

Innovation involves the incorporation of new ideas into the operations of the firm. Innovation enables the firm to maintain and enhance its competitive position in the market. The sample's perception of innovation as a success factor is exhibited in Table 24. Only 30 percent of the sampled firms regarded innovation as not or slightly essential to the success of small black-owned businesses. In contrast, more than half (52.5\%) of the firms considered this factor as very or most essential for success. The small business entrepreneur needs to be innovative in producing goods and services in the modern complex and competitive economy. 
Table 24

Innovation as a Success Factor in Black-owned Firms $(\mathrm{N} \equiv 40)$

Frequency

Not at all essential

slightly essential

Essential

Very essential

Most essential
2

10

7

14

$\underline{z}$

Total

40
5.0

25.0

17.5

35.0

17.5

Percent

100.0

Creativity is the process in which the entrepreneur's actions are in anticipation of change. Creativity is best fostered in a dynamic and tolerant atmosphere (Appleby, 1982). The sample's evaluation of creativity as a success factor is presented in Table 25.

Table 25

Creativity as a Success Factor in Black-owned Firms (N $\equiv 40$ ) Frequency Percent

Not at all essential

2

5.0

slightly essential

32.5

Essential

Very essential

8

20.0

Most essential

10

25.0

Total

40

100.0 
As shown in Table 25, only five percent of the respondents considered creativity as unessential to the success of small black-owned firms. In contrast, nearly half (45\%) of the sampled firms evaluated creativity as very or most essential as a success factor in black-owned businesses. The managerial competence of the entrepreneur in planning, organizing and controlling the operations of the firm is crucial for success. Table 26 demonstrates how the sampled entrepreneurs viewed managerial competence as a success factor. Less than three percent (2.5\%) of the sampled firms regarded managerial competence as slightly essential to the success of small black-owned enterprises. In contrast, 95 percent viewed this factor as very or most essential for success. The competent manager is likely to make the most appropriate decisions in managing the operations of the firm. Table 26

Managerial Competence as a Success Factor in Black-owned Firms $(N \equiv \underline{40)}$

\section{Frequency}

Not at all essential

Slightly essential

Essential

Very Essential

Most essential
0

1

1

12

26

40
Percent

0.0

2.5

2.5

30.0

65.0

Total

100.0 
In addition to managerial competence, the small entrepreneur also needs the skills in managing the business, viz. planning, organizing, directing, staffing, and controlling. The evaluation of managerial skills in the success of small black-owned enterprises is shown in Table 27. Whereas less than one-tenth $(7.5 \%)$ of the respondents regarded managerial skills as merely essential for the success of small black-owned enterprises, over half (55\%) considered the factor most essential. The efficient utilization of managerial skills might ensure that resources are effectively deployed in the production process, and probably sound decisions would be taken to enhance the market position of the firm.

Table 27

Managerial Skills as a Success Factor in Black Firms (N $\equiv \underline{40)}$

\begin{tabular}{lcc}
\hline & Frequency & Percent \\
Not at all essential & 0 & 0.0 \\
Slightly essential & 0 & 0.0 \\
Essential & 3 & 7.5 \\
Very essential & 15 & 37.5 \\
Most essential & $\underline{22}$ & $\underline{55.0}$ \\
& $\underline{40}$ & $\underline{100.0}$ \\
\hline
\end{tabular}

As the small enterprise grows, it eventually becomes complex as new functional departments are created, additional 
staff is engaged, and more lines of authority and communication are established. The need for interpersonal skills then becomes very important. The value attributed to interpersonal skills in the success of small black-owned firms is presented in Table 28. One-tenth of the sampled firms evaluated interpersonal skills as slightly essential to the success of black-owned firms. In comparison, nearly two-thirds $(62.5 \%)$ considered this factor as very or most essential. The availability of interpersonal skills is extremely important to small black-owned enterprises that are on the vendor lists of state and local governments as they have to negotiate contracts regularly.

Table 28

Interpersonal Skills as a Success Factor in Black-owned Firms $(\mathbf{N} \equiv \underline{40)}$

Frequency

Not at all essential

Slightly essential

Essential

Very essential

Most essential
0

4

11

12

13

40
Percent

$$
0.0
$$

10.0

27.5

30.0

32.5

100.0

Tota1$$
\text { 100. }
$$ 
policies, availability of employee skills, existing technologies, credit terms etc. Table 29 indicates how environmental characteristics were regarded by the sampled firms as a success factor. Whereas less than three-tenths (27.5\%) of the sampled firms viewed the characteristics of the enviromment as not or slightly essential for success in small black-owned enterprises, nearly half (45\%) considered this factor as very or most essential. Whenever environmental characteristics are favorable, the small entrepreneur seems to have a greater opportunity for success. On the other hand, whenever these characteristics are unfavorable the small entrepreneur should exercise good judgment in managing the enterprise.

Table 29

Environmental Characteristics as a Success Factor in Black-owned Firms $(N \equiv \underline{40)}$

Frequency

Not at all essential

Slightly essential

Essential

Very essential

Most essential
1

10

11

11

Z
Percent 2.5 25.0

27.5 27.5 17.5

Total 40 100.0 
chief executive officer in the case of a corporation) in the running of the small firm provides technical, managerial/ entrepreneurial skills, and business experiences which are often needed for success. The respondents' evaluation of the involvement of top management in the operations of the firm, as a success factor, is presented in Table 30 . Only five percent of the sampled entrepreneurs viewed top management participation in the operations of a small business as unessential for success. In contrast, over three quarters (77.5\%) considered this factor as very or most essential. The participation of top management is particularly crucial as small enterprises have to use, with maximum efficiency, al1 the resources at their disposal in the effort to ensure growth and success.

Table 30

The Involvement of Top Management as a success factor in Black-owned Firms $(\mathrm{N} \equiv 40)$

Frequency

Not at all essential

Essential

very essential

Most essential
2

7

12

19

40
Percent

$$
5.0
$$

17.5

30.0

47.5

Tota1 100.0 
crucial to the viability of small enterprises. The evaluation of that factor by the respondents is indicated in Table 31. Table 31

The Ski1ls of Key Employees as a Success Factor in Black-owned Firms $(\mathbb{N} \equiv 40)$

\section{Frequency}

Not at a 11 essential

slightly essential

Essential

Very essential

Most essential
0

1

7

20

12

Total 40
Percent

0.0

2.5

17.5

50.0

30.0

100.0

Table 31 shows that whereas less than three percent (2.5\%) of the sampled firms assessed the skills of key employees (such as supervisors and foremen) as slightly essential, 80 percent viewed this factor as very or most essential for success in small black-owned firms. The entrepreneur often gets plans implemented through the cooperation of the employees. If the latter lack the required skills, they are unlikely to perform efficiently.

The entrepreneur usually sets priorities to ensure that scarce resources are allocated to activities which demand immediate attention, and to implement projects in a structured manner. The sample's assessment of the setting of 
priorities as a success factor in black-owned businesses is shown in Table 32 . Whereas a quarter of the sample considered the factor as not or slightly essential for success, more than half $(52.5 \%)$ regarded it as very or most essential. Table 32

The Setting of Priorities as a Success Factor in Black-owned Firms $(N \equiv 40)$

\section{Frequency}

Not at all essential

slightly essential

Essential

Very essential

Most essential
1

9

9

10

11

Total 40
Percent

2.5

22.5

22.5

25.0

27.5

100.0

Some researchers have concluded that the economic survival of small enterprises depends significantly on the maintenance of a long range orientation. Short term planning is insufficient to support the competitive position of small enterprises in the modern economy. The maintenance of a long range orientation as a success factor is evaluated in Table 33. Only one fifth of the sample viewed the maintenance of a long-range orientation as slightly essential for success in black-owned firms. In comparison, nearly two-thirds (62.5\%) regarded this factor as very or most essential. Small black 
entrepreneurs who intend to launch out into the national market should maintain a long-range perspective; decisions should be based on both short and long term business conditions.

Table 33

Maintenance of a Long Range orientation as a Success Factor in Black-owned Firms $(\mathrm{N} \equiv 40)$

\section{Frequency}

Not at all essential

Slightly essential

Essential

Very essential

Most essential
0

8

7

8

17

Total 40
Percent

$$
0.0
$$

20.0

17.5

20.0

$\underline{42.5}$

100.0

In summary, the data pertaining to selected critical factors that are essential for success in small enterprises were described in this section of the study. The percentages of the respondents, in rank order, rating the factors as very or most essential to success in small black-owned firms are: Managerial competence (95\%), managerial skills (93\%), training ( $80 \%)$, skills of key employees ( $80 \%$ ), involvement of top management (78\%), entrepreneur as final decision-maker (73\%), development (68\%), flexible informal control system (68\%), entrepreneurial behavior (65\%), creativity (65\%), 
interpersonal skills (63\%), maintenance of a long range orientation (63\%), communication system (61\%), innovation (53\%), setting of priorities (53\%), education (50\%), and environmental characteristics $(45 \%)$. Whereas managerial competence, managerial skills, training, and the skills of key employees are rated highly as success factors in small black-owned enterprises, innovation, setting of priorites, education and environmental characteristics are not evaluated as very significant.

\section{Third Research Question}

Tables 34 through 42 summarize the data relating to the third question in this study which is: Is there any relationship between the amount of critical factors and success in small black-owned firms? The critical factors for which data are described are: venture/reserve capital, financial/strategic planning, internal $R$ \& $D$, modern equipment, consultancy, departmentation, managerial skills, employee skills, and entrepreneurial skills.

Many small enterprises are formed to implement projects utilizing venture and reserve capital. Venture capital is that which is invested in high-risk projects which are likely to generate large returns. Reserve capital is accumulated by annually ploughing back a percentage of profit into a special fund for specific purposes. The assessment of the availability of venture and reserve capital is illustrated in Table 34 . Whereas less than three percent $(2.5 \%)$ of the 
sample regarded venture and reserve capital as not or slightly lacking in small black-owned enterprises, over 80 percent $(82.5 \%)$ viewed this factor as very or most lacking. Any deficiency of venture/reserve capital would impair the firm's capacity to exploit investment opportunities.

Table 34

Availability of Venture and Reserve Capital as a critical Factor in Black-owned Firms $(\mathrm{N} \equiv \underline{40)}$

\section{Frequency}

Not at all lacking

slightly lacking

Lacking

Very lacking

Most lacking
0

1 6

10

$\underline{23}$

Total

$\underline{40}$
Percent

0.0

2.5

15.0

25.0

$\underline{57.5}$

100.0

Financial and strategic planning skills are crucial to the effective management of the small firm. Table 35 shows the evaluation of the availability of systematic financial and strategic planning skills in small black-owned businesses. Whereas less than one-tenth (7.5\%) of the sampled firms felt that the skills were slightly lacking in small black-owned firms, three quarters agreed that they were very or most lacking. 
Table 35

Availability of Financial and Strategic Planning skills as a Critical Factor in Black-owned Firms $(N \equiv 40)$

Erequency

Not at al1 lacking

Slightly lacking

Lacking

Very lacking

Most lacking
0

3

7

17

13

Tota1
Percent

0.0

7.5

17.5

42.5

32.5

100.0

The internal research and development ( $R$ \& D) function enables the smal1 entrepreneur to keep abreast of new technologies. Table 36 shows the sample's evaluation of internal Research and Development (R \& D) as a success factor. Approximately one-tenth (12.5\%) of the sample thought that internal Research and Development ( $R$ \& $D$ ) skills were not or slightly lacking in small black-owned firms. In constrast, more than 70 percent $(72.5 \%)$ viewed these skills as very or most lacking. Internal $R$ \& $D$ assists the firm in establishing goals for the long run, which provide direction for the enterprise. Internal $R$ \& $D$ also aids the entrepreneur in the decision-making process. 
Table 36

Availability of Internal $\underline{R} \underline{\text { s }}$ D as a critical Factor in Black-owned Firms $(N \equiv \underline{N} \equiv)$

Not at all lacking

slightly lacking

Lacking

Very lacking

Most lacking

\section{Frequency}

2

3

6

15

14

$\underline{40}$
Percent

5.0

7.5

15.0

37.5

$\underline{35.0}$

Total

100.0

The respondents'evaluation of the availability of modern equipment in black-owned firms is indicated in Table 37. Table 37

Availability of Modern Equipment as a Critical Factor in Black-owned Firms $(N \equiv \underline{N} \equiv)$

Not at all lacking

Slightly lacking

Lacking

Very lacking

Most lacking

\section{Frequency}

1

6

16

11

6

40
Percent

2.5

15.0

40.0

27.5

15.0

Total

100.0 
As presented in Table 37, whereas less than two-tenths (17.5\%) of the sample felt that the amount of modern equipment in small black-owned firms was not or slightly lacking, more than four-tenths (42.5\%) considered this factor as very or most lacking. The employment of modern equipment would likely reduce the operating costs of the small firm, increase productive efficieny, and expand the volume of output. It seems that modern equipment is relatively not a very scarce factor in black-owned firms as less than one-fifth (15\%) of the respondents estimated the factor as most lacking.

Consultants provide technical assistance to firms in many management areas. The assessment of the availability of consultants in small black firms is revealed in Table 38 . Table 38

Availability of Consultants as a critical Factor in Black-owned Firms $(\mathrm{N} \equiv 40)$

Frequency

Not at all lacking

Slightly lacking

Lacking

very lacking

Most lacking
2

4

10

12

12

40
Percent

$$
\begin{array}{r}
5.0 \\
10.0 \\
25.0 \\
30.0 \\
30.0 \\
\hline
\end{array}
$$

100.0 
Table 38 indicates that whereas less than a fifth of the sampled firms thought that consultants were not or slightly lacking in small black-owned firms, 60 percent concluded that the skills were very or most deficient. Small entrepreneurs often cannot afford the services of consultants. Therefore, many small black entrepreneurs operate without guidance in critical areas of management.

Departmentation is the grouping of tasks or functions within the enterprise. The departmentation of the small business during the growth phase would tend to relieve the entrepreneur of many details of management, enabling him to concentrate on the imperatives of expansion. The supply of departmentation skills in small black-owned firms, as perceived by the respondents, is indicated in Table 39. Table 39

Availability of Departmentation Skills as a Critical Factor in Black-owned Firms $(N \equiv \underline{40)}$

\section{Frequency}

Not at all lacking

Slightly lacking

Lacking

Very lacking

Most lacking
4

1

15

14

$\underline{6}$

Total

40
Percent

10.0

2.5

37.5

35.0

15.0 100.0 
Table 39 shows that, whereas approximately one-tenth (12.5\%) of the subjects felt that small black-owned firms were not or slightly lacking in departmentation skills, half considered these skills as very or most lacking. A lack of these skills might hinder the growth of the small firm which needs functional departments during the rapid growth phase. Managerial skills (which include planning, organizing, directing, staffing, and controlling) are generally regarded as vital for success in the small firm. Table 40 illustrates the degree to which the respondents considered managerial skills as available in black-owned firms. Whereas 30 percent of the sampled firms felt that managerial skills were not or slightly lacking in black firms, more than four-tenths (42.5\%) viewed this factor as very or most lacking. Table 40 Availability of Managerial skills as a Critical Factor in Black-owned Firms $(N \equiv 40)$

\begin{tabular}{|c|c|c|}
\hline & Frequency & Percent \\
\hline Not at a11 lacking & 4 & 10.0 \\
\hline slightly lacking & 8 & 20.0 \\
\hline Lacking & 11 & 27.5 \\
\hline Very lacking & 12 & 30.0 \\
\hline Most lacking & $\underline{5}$ & 12.5 \\
\hline & Tota1 & 100.0 \\
\hline
\end{tabular}


The evaluation of the availability of employee skills in small black-owned firms is presented in Table 41.

Table 41

Availability of Employee Skills as a critical Factor in Black-owned Firms $(N \equiv \underline{N} \equiv)$

Frequency

Not at all lacking

slightly lacking

Lacking

Very lacking

Most lacking
4

10

19

6

1

40
Percent

10.0

25.0

47.5

15.0

2.5

100.0

Tota1

Table 41 reveals that more than three-tenths (35\%) of the sample agreed that employee skills were not or slightly lacking in small black-owned firms. In contrast, less than two-tenths (17.5\%) viewed these skills as very or most lacking. It is likely that the respondents felt they had an adequate supply of efficient employees.

The skills of the entrepreneur are crucial for success in the small black-owned firms. The assessment of the availability of entrepreneurial skills in the sampled firms is outlined in Table 42 . Whereas nearly one-third (32.5\%) of the sample thought that the supply of entrepreneurial skills was not or slightly lacking, less than three-tenths (27.5\%) 
viewed this factor as very or most lacking.

Table 42

Availability of Entrepreneurial skills as a Critical Factor in Black-owned Firms $(N \equiv 40)$

\section{Frequency}

Not at all lacking

Slightly lacking

Lacking

Very lacking

Most lacking
Total
7

6

16

8

$\underline{3}$

$\underline{40}$
Percent

17.5

15.0

40.0

20.0

$\underline{7.5}$

100.0

The data concerning the availability of selected

critical factors in small black-owned firms were described in this section of the study. The percentages of the respondents, in rank order, rating the critical factors as very or most lacking in small black-owned firms were: venture /reserve capital (83\%), financial/strategic planning (75\%), internal $R$ \& $D(73 \%)$, consultants $(60 \%)$, departmentation skills (50\%), modern equipment (43\%), managerial skills (43\%), entrepreneurial skills (28\%), and employee skills (18\%). Whereas venture/reserve capital, financial/strategic planning, and internal $R \& D$ were considered very or most lacking in black-owned firms, employee and entrepreneurial skills were not so regarded by the respondents. 


\section{Fourth Research Question}

The fourth research question is: Is staff development one of the determinants of success in small black-owned firms? The description of the data relating to the fourth question is presented below.

More than nine-tenths (95\%) of the sampled firms agreed that staff development was one of the determinants of success in small enterprises. Three-tenths of the sample considered staff development as an extremely significant success factor. The amount of staff training provided by the firms during the period 1985 to 1989 is outlined in Table 43 . Table 43

Amount of Staff Training Provided in Period $1985 / 89$ by Black-owned Firms $(N \equiv \underline{\underline{N}} \equiv)$

Length of Training

More than three years

One to three years

Less than one year
Frequency

12

2

$\underline{26}$

Total 40
Percent

30.0

5.0

$\underline{65.0}$

100.0

Table 43 shows that about two-thirds (65\%) of the sampled firms offerred training to employees for less than one year in the period 1985 to 1989. In contrast, nearly one third (30\%) of the sampled firms provided training opportunities to their employees in more than three years. 
In summary, the overwhelming majority (95\%) of the respondents considered staff development as a success factor in small black-owned firms. Nearly two-thirds (65\%) of the sampled entrepreneurs provided staff training for less than one year in the period 1985 to 1989 , compared to about one-third (30\%) who did so for more than three years.

\section{Fifth Research Question}

The fifth research question is : Are small black entrepreneurs aware of the role of staff development in the success of their firms? The data relating to the fifth question are summarized in this section of the study.

Table 44 presents the responses of the sampled entrepreneurs to the question: Are you aware of the role that staff development can play in the success of your firm? Table 44

Awareness of the Role of staff Development in the Success of Black-owned Firms $(\mathbb{N} \equiv \underline{40)}$

Responses

Not at all aware

slightly aware

Aware

Very aware

Extremely aware
Frequency

0

2

13

17

$\underline{8}$

40
Percent .0 5.0 32.5 42.5 $\underline{20.0}$ Total 100.0 
Table 44 indicates that all of the sampled entrepreneurs expressed awareness of the role of staff development in the success of their firms. However, whereas less than one-tenth (5\%) of the respondents were slightly aware, one-fifth were extremely aware of staff development as a success factor. This awareness is likely to motivate small black-owned firms to provide their employees with opportunities for development.

\section{Sixth Research Question}

The sixth research question in this study is: Does the leadership styles of small black entrepreneurs affect success in their firms?

Table 45 indicates the leadership styles of the sampled small black entrepreneurs.

Table 45

Leadership Styles of Small Black Entrepreneurs $(N \equiv \underline{N}$ )

Styles

Frequency

Percent

Owner and workers make

business decisions

26

65

Owner alone makes decisions

14

$\underline{35}$

Total

40

100

Table 45 shows that in almost two-thirds (65\%) of the sample, the leadership style of the entrepreneurs was democratic as the owners and the workers collaborated in 
making important business decisions. In the other firms (35\%), the owners alone decided on critical matters.

Table 46 presents the responses of the sampled entrepreneurs to the question: Does your leadership style affect the success of your firm?

Table 46

Effect of Leadership Styles on Success in Black-owned Firms $(\underline{N} \equiv \underline{40)}$

Responses

Yes

No
Frequency

32

$\underline{8}$
Percent

80

$\underline{20}$

Total 40

100

Table 46 shows that 80 percent of the sampled entrepreneurs declared that their leadership styles affected the success of their firms. It seems that the respondents realized that the success of the firms depended significantly on the quality of their leadership.

The types of staff training provided by the sampled firms are presented in Table 47 . On-the-job training was the most prevalent form of staff training, as it was provided in approximately two-thirds $(67.5 \%)$ of the firms. One-fifth of the sampled firms did not provide any specific training for the employees. In addition, very little emphasis was placed on formal staff training by management in the sampled firms. 
Table 47

Types of Staff Training Provided by Black-owned Firms

$\underline{(N} \equiv \underline{40)}$

Types

On-the-job training

Formal training within specified

institutions

Formal training within the firms No specific training
Frequency

27
Percent

67.5
3

2

$\underline{8}$

$\underline{40}$
7.5

5.0

$\underline{20.0}$

Total

100.0

Seventh Research Question

The seventh research question in this study is: Is there any relationship between HRD skills and success in black-owned firms? Table 48 shows the percentages of the firms that possessed specific staff development skills within their staffs. The data reveal clearly that the sampled firms, as a group, possessed relatively low levels of the staff development skills targetted in the interviews. The skills in which the firms were marginally equipped were in the evaluation of instruction ( $60 \%$ ) and communication (55\%). A significant deficiency of HRD skills in the sampled firms existed in areas such as the analysis of job characteristics, the creation of courses and learning packages, determination of instructional resources, and in instructional planning. 
Table 48

Staff Development Skills Within Black-owned Firms $(N \equiv 40)$

Types of skills

Evaluate instruction

Communicate in visual, oral forms

Demonstrate interpersonal behavior

Assess learner characteristics

Determine projects for staff development

Sequence learner outcomes

Sequence learner activities

Write statements of learner outcomes

Analyse learning setting

specify instructional strategies

Analyse characteristics of jobs

Create courses, learning packages

Determine instructional resources

Plan and monitor instructional development
Frequency Percent

24

60.0

22

55.0

19

48.0

16

40.0

13

33.0

12

30.0

12

30.0

10

25.0

923.0

923.0

923.0

$9 \quad 23.0$

820.0

7

18.0

In this section of this study, the data pertaining to the total sample for the Interview Study (Phase Two) were described. Research Questions Two through Seven were used to organize the description of the data. The first null hypothesis was tested in the questionnaire component (Phase one) of this study. The remaining six null hypotheses are tested in the sections below. 
Testing of Second Null Hypothesis

The second null hypothesis in this study is: The critical factors essential for success are identical in all small black-owned firms.

A comparison is drawn between the most successful and the least successful small black-owned firms relative to the success factors identified in chapter Two. In this way it is discerned whether or not the success factors are identical for both groups of small black-owned enterprises.

Table 49 shows the comparison of the most and the least successful small black-owned enterprises on the selected critical factors. The mean for the most successful black-owned firms in respect to training is 4.25 , that for the least successful is 4.10 , and the observed significance level is 5.66. As the observed significance level of $.566>p$ $=.05$, there is no significant difference between the groups on training as a success factor. Thus the null hypothesis is not rejected. Small black entrepreneurs generally realize the value of training as a success factor.

Table 49 shows that for education the mean for the most successful small black-owned firms is 3.95 , that for the least successful is 3.15 , and the observed significance level is .018 . As the observed significance level of $.018<\mathrm{p}=$ .05 , the difference between the groups on the variable education is significant. Thus the null hypothesis is rejected. The most successful black entrepreneurs seems to 
have a higher regard for education than the least successful. Table 49

t-test of the Differences Between the Most and Least Successful Small Black-owned Firms on Selected Variables

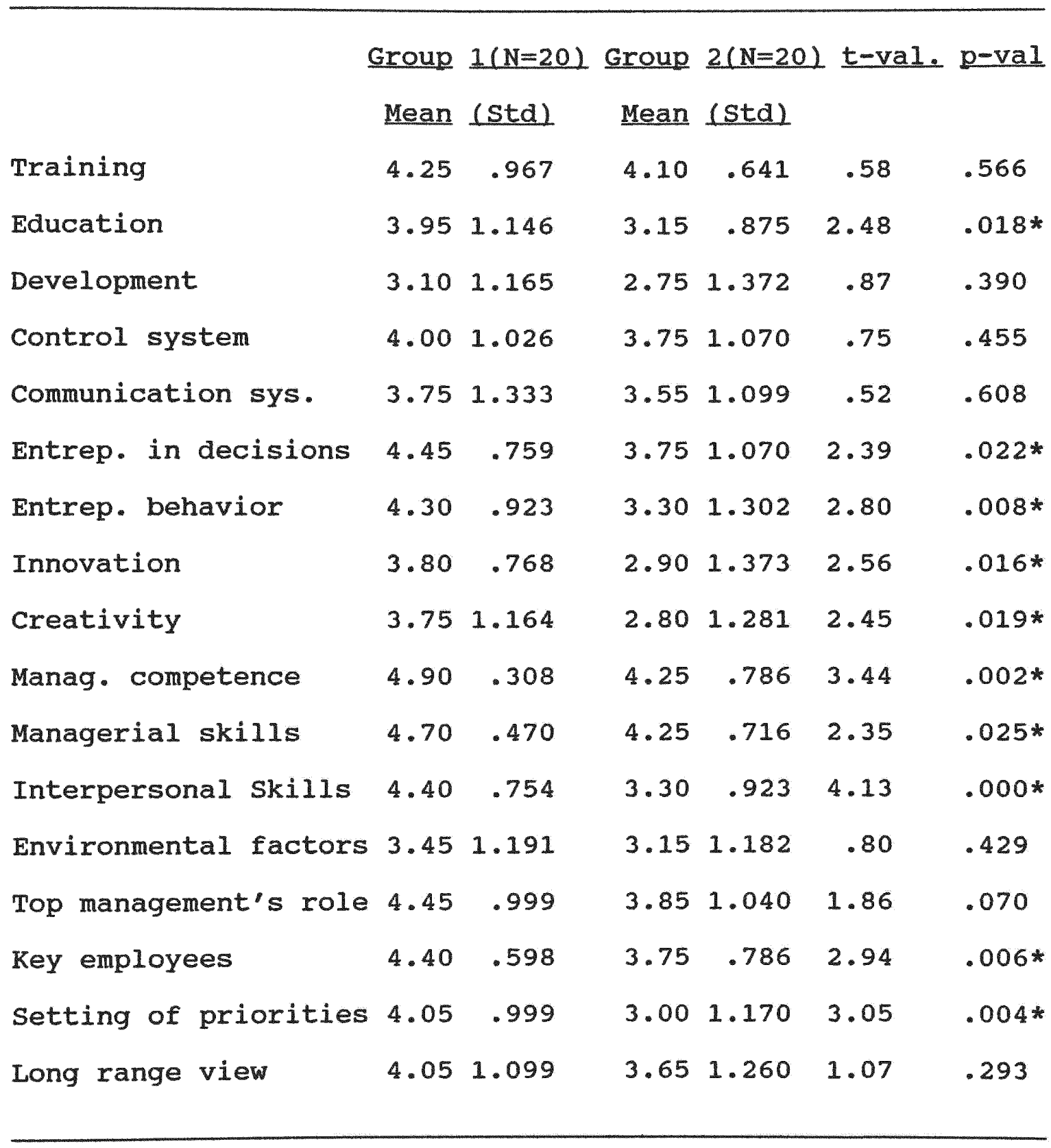

* Prob. < .05 level of significance 
Table 49 indicates that for the variable development, the mean for the most successful firms is 3.10, that for the least successful is 2.75 , and the observed significance level is .390. As the observed significance level of $.390>p=$ .05 , there is no significant difference between the groups. Therefore, the null hypothesis is not rejected. Both groups of entrepreneurs have not concentrated sufficiently on the need to link the growth of the firm to that of the personnel. Table 49 reveals that for the variable "flexible informal control system", the mean for the most successful firms is 4.0 , that for the least successful is 3.75 , and the observed significance level is .455. As the observed significance level of $.455>p=.05$, the difference between the two groups on the variable "flexible informal control system" is not significant. Thus the null hypothesis is not rejected. Apparently degree of success does not influence the attitude of small entrepreneurs to the control function.

As shown in Table 49, for the variable "communication system" the mean for the most successful firms is 3.75 , for the least successful the mean is 3.55 , and the observed significance level is .608 . As the observed significance level of $.608>\mathrm{p}=.05$ the difference between the groups is not significant. Consequently, the null hypothesis is not rejected. The level of success is unrelated to the small firm's approach to the communication function.

For the variable "the entrepreneur as final 
decision-maker", the mean for the most successful small black-owned firms is 4.45, that for the least successful is 3.75 , and the observed significance level is .022 . As the observed significance level of $.022<p=.05$, the difference between the two groups on the variable "entrepreneur as final decision-maker" is significant. Thus the null hypothesis is rejected. The most successful small black firms view more strongly the role of the entrepreneur in decision-making.

Table 49 shows that for the variable "entrepreneurial behavior", the mean for the most successful firms is 4.30 , that for the least successful is 3.30 , and the observed significance level is .008 . As the observed significance level of $.008<\mathrm{p}=.01$, the difference between the two groups is significant. Thus the null hypothesis is rejected. The most successful black-owned firms are more convinced that entrepreneurial behavior is a vital success factor.

Table 49 indicates that for the variable innovation, the mean for the most successful firms is 3.80 , that for the least successful is 2.90 , and the observed significance level is .016. As the observed significance level of $.016<p=$ .05 , the difference between the two groups on the variable innovation is significant. Therefore, the null hypothesis is rejected. The most successful entrepreneurs apparently endeavour to be more innovative, compared to the least successful.

Table 49 discloses that the mean for the most successful 
black firms on the variable creativity is 3.75 , that for the least successful is 2.80 , and the observed significance level is .019. As the observed significance level of $.019<p=$ .05 , the difference between the two groups in respect to creativity is significant. Therefore, the null hypothesis is rejected. Compared to the least successful, the most successful small black-owned firms seem to be more creative.

As presented in Table 49, for the variable "managerial competence" the mean for the most successful small black firms is 4.90 , for the least successful the mean is 4.25 , and the observed significance level is .002 . As the observed significance level of $.002<p=.01$, the difference between the two groups in respect to managerial competence is significant. Therefore, the null hypothesis is rejected. It seems that the most successful small black entrepreneurs have more managerial competence, compared to the least successful. For the variable "managerial skills", the mean for the most successful firms is 4.70 , that for the least successful is 4.25 , and the observed significance level is .025 . As the observed significance level of $.025<p=.05$, the difference between the two groups concerning managerial skills is significant. Thus the null hypothesis is rejected. The most successful small firms are likely to have a greater pool of managerial skills, in comparison to the least successful firms.

As presented in Table 49, for interpersonal skills the 
mean for the most successful small black-owned firms is 4.40 , that for the least successfu is 3.30 , and the observed significance level is .000 . As the observed significance level of $.000<p=.01$, the difference between the two groups relative to interpersonal skills is significant. Therefore, the nuIl hypothesis is rejected. The most successful small black entrepreneurs seem to be more adept at interpersonal skills than the least successful.

A scrutiny of Table 49 shows that for the variable "environmental characteristics" the mean for the most successful small black-owned firms is 3.45 , that for the least successful is 3.15 , and the observed significance level is .429. As the observed significance level of $.429>p=$ .05 , the difference between the two groups on the variable "environmental characteristics" is not significant. Thus the null hypothesis is not rejected. There is hardly any difference between the most and the least successful small black entrepreneurs concerning their evaluation of environmental characteristics as a success factor in small businesses.

For the variable "top management involvement", the mean for the most successful black-owned firms is 4.45 , for the least successful it is 3.85 , and the observed significance level is .070 . As the observed significance level of $.070>p$ $=.05$, the difference between the two groups on the variable "top management involvement" is not significant. Therefore, 
the null hypothesis is not rejected. Black entrepreneurs apparently do not differ significantly in their perception of the role of top management as a success factor in the operations of a business.

As shown in Table 49, for the variable "skills of key employees" the mean for the most successful firms is 4.40 , that for the least successful is 3.75, and the observed significance level is .006 . As the observed significance level of $.006<p=.01$, the difference between the two groups concerning the skills of key employees is significant. Thus the null hypothesis is rejected. The most successful entrepreneurs have a higher evaluation of the skills of key employees as a success factor in comparison to the least successful.

Table 49 indicates that for the variable "setting of priorities", the mean for the most successful small black firms is 4.05 , that for the least successful is 3.00 , and the observed significance level is .004 . As the observed significance level of $.004<p=.01$, the difference between the two groups on the setting of priorities is significant. Consequently, the null hypothesis is rejected. Small enterprises which engage in the setting of priorities are more likely to be successful in that they would tend to address matters in order of importance.

For the variable "maintenance of a long range orientation", the mean for the most successful small black 
firms is 4.05 , for the least successful the mean is 3.65 , and the observed significance level is .293. As the observed significance level of $.293>p=.05$, the difference between the two groups relative to the maintenance of a long range orientation is not significant. Therefore, the null hypothesis is not rejected. Probably small black entrepreneurs in general have adopted the same attitude to a long range perspective in the management of their firms. Black-owned firms which intend to launch out into the national and foreign markets, which are very complex and competitive, probably would have to maintain a long term perspective in order to be successful.

In summary, it has been established that differences between the most successful and the least successful small black-owned enterprises in Dade County exist on the following factors: Education, entrepreneur as final decision-maker, entrepreneurial behavior, innovation, creativity, managerial competence, managerial skills, interpersonal skills, skills of key employees, and the setting of priorities from the early phase of the business. Therefore, Hypothesis Two is rejected because the factors essential for success are not identical for all small black-owned businesses. 


\section{Testing of Third Null Hypothesis}

In this section of this study the third null hypothesis is tested. The third null hypothesis is: There is no relationship between the amount of selected critical factors and success in small black-owned firms.

Crosstabulation was employed to show the sample's assessment of specific critical factors to the success of the sampled firms. Those critical factors have always been regarded as vital to the success of small firms. A comparison is made between the most successful and least successful small black-owned firms in order to determine if they were relatively lacking in the specific factors. The Chi-Square test is utilized to measure the relationship between the selected critical factors and success in the sampled firms.

The assessment of the scarcity of venture and reserve capital in the sampled firms is provided in Table 50. Whereas 70 percent of the most successful small black-owned firms considered that venture and reserve capital were most deficient in their firms, less than a half (45\%) of the least successful respondents reported a shortage of the resource. Generally, the resource was lacking in both groups of black-owned firms. As the observed significance level of $.297>p=.05$, the conclusion is that the relationship between venture/reserve capital and success is not significant. It seems that black entrepreneurs generally have not relied too heavily on venture and reserve capital to 
finance their business operations.

Table 50

Comparison of Venture/Reserve Capital and Success in Black-owned Firms $(N \equiv \underline{40)}$

\section{Success}

Most

Least

Venture/Reserve Capital

Not at all lacking

Slightly lacking

Lacking

Very Lacking

Most Lacking

Total

Chi-Square

Pearson
Value

3.68696
Successful

$0 \quad(0 \%)$

$0 \quad(0 \%)$

$3(15 \%)$

$3(15 \%)$

$14(70 \%)$

$\underline{20}$

$D / F$

3
Successful

$0 \quad(0 \%)$

$1(5 \%)$

$3(15 \%)$

$7(35 \%)$

$2(45 \%)$

$\underline{20}$

Significance

.297

The sample's evaluation of the deficiency of systematic financial and strategic planning is presented in Table 51. Financial and strategic planning does provide a framework for guiding entrepreneurial thinking and actions. The function provides direction for the enterprise, and assists management with the task of deploying the resources of the enterprise in the long run. The small entrepreneur that engages in systematic financial and strategic planning as a matter of policy is likely to have an efficient system for 
decision-making within the firm.

Table 51

Comparison of Systematic Financial/Strategic Planning and Success in Black-owned Firms $(N \equiv 40)$

\section{Success}

Systematic Financial

SStrategic Planning

Slightly lacking

Lacking

Very Lacking

Most lacking

Total 20

Most

Successful

$2(10 \%)$

$5(25 \%)$

$6(30 \%)$

$7(35 \%)$

value

$D / F$

3.16656

Pearson

3
Least

Successful

1 (5\%)

2 (10\%)

11 (55\%)

$6 \quad(30 \%)$

$\underline{20}$

.36665

A perusal of Table 51 indicates that whereas a quarter of the most successful respondents considered that there was insufficient systematic financial and strategic planning in their firms, only one-tenth of the least successful firms did so. However, nearly two-thirds (65\%) of the most successful firms reported the factor as very or most lacking, compared to 85 percent of the least successful. Generally, both the most successful and the least successful firms declared the factor as deficient. As the observed significance level of $.36665>p=.05$, the relationship between financial/ 
strategic planning and success is not considered significant. The sample's assessment of the scarcity of internal $R$ \& $D$ is indicated in Table 52. One-tenth of the most successful entrepreneurs did not regard internal $R$ \& $D$ as lacking in their firms. Whereas only a quarter of the most successful firms viewed the factor as most lacking, nearly a half (45\%) of the least successful firms did so. As the observed significance level of $.033<p=.05$, the relationship between internal $R \& D$ and success is significant.

Table 52

Comparison of Internal $\underline{R} \underline{\&} \underline{D}$ and Success in Black-owned Firms $(N=40)$

\section{Success}

Most

Internal $\underline{\mathrm{R}} \underline{\&} \underline{\mathrm{D}}$

Not at all lacking

Slightly lacking

Lacking

Very lacking

Most lacking

Total

Value

10.47619

Successful

$2(10 \%)$

$3(15 \%)$

5 (25\%)

5 (25\%)

5 $(25 \%)$

$\underline{20}$

Chi-Square

Pearson
$D / F$

4
Least

Successful

$0 \quad(0 \%)$

$0 \quad(0 \%)$

1 (5\%)

$10(50 \%)$

2 $(45 \%)$

$\underline{20}$

Significance

.033 
Table 53 indicates the degree to which the respondents regarded modern equipment as a scarce resource in their firms. There was a slight difference in the extent to which modern equipment is regarded as a scarce resource by both groups of respondents. Forty percent in both groups considered the factor as lacking, and 15\% in both regarded it as most lacking. As the observed significance level of .647 $>p=.05$, the relationship between modern equipment and success in black-owned firms is not significant.

Table 53

Comparison of Modern Equipment and Success in Black-owned $\underline{\text { Firms }}(\mathbb{N} \equiv \underline{40)}$

\section{Success}

Most Successful

Modern Equipment

Not at all lacking

Slightly lacking

Lacking

Very lacking

Most lacking

$$
\text { Chi-Square }
$$

Pearson
Total

Value

2.48485
1 (5\%)

$4(20 \%)$

$8(40 \%)$

$4(20 \%)$

$3(15 \%)$

$\underline{20}$

$\mathrm{D} / \mathrm{F}$

4
Least Successful

$0 \quad(0 \%)$

2 (10\%)

8 (40\%)

7 (35\%)

$7(15 \%)$

20

Significance .647 
in the sampled firms is shown in Table 54. Whereas one-tenth of the most successful firms reported consultancy skills as most lacking, half of the least successful respondents did so. As the observed significance level of $.041<p=.05$, the relationship between consultancy skills and success in small black-owned firms is considered marginally significant.

Table 54

Comparison of Consultancy Skills and Success in Black-owned Firms $(N \equiv \underline{40)}$

\section{Success}

Most

Successful

$2(10 \%)$

$3(15 \%)$

7 (35\%)

6 (30\%)

$2(10 \%)$

$\underline{20}$

Total

Chi-Square

Pearson
Value

9.93333
Least

Successful

$0 \quad(0 \%)$

1 (5\%)

3 (15\%)

$6(30 \%)$

$10(50 \%)$

20

Significance .041

The sample's perception of the adequacy of departmentation skills in small black-owned firms is shown in Table 55. One fifth of the most successful firms reported that departmentation skills were present in their 
enterprises; and less than one-tenth (5\%) stated that they were slightly lacking. Whereas departmentation skills were most lacking in one-tenth of the most successful firms, they were deficient in one-fifth of the least successful. As the observed significance level of $.197>p=.05$ the relationship between departmentation skills and success in small black-owned firms is not significant.

Table 55

Comparison of Departmentation skills and success in Black-owned Firms $(N \equiv \underline{N} \equiv)$

\section{Success}

Most Successful

Departmentation Skills

Not at all lacking

Slightly lacking

Lacking

Very lacking

Most lacking

Total

Chi-Square

Pearson
Value

6.01905
$4(20 \%)$

1 (5\%)

7 (35\%)

6 (30\%)

2 $(10 \%)$

$\underline{20}$

D/F

6
Least Successful

$0 \quad(0 \%)$

- $(0 \%)$

8 (40\%)

$8(40 \%)$

$4(20 \%)$

$\underline{20}$ Significance .197

The availability of managerial skills in the sampled firms is indicated in Table 56. The skills were adequate in one-fifth of the most successful black-owned firms. Whereas 
one-tenth of the most successful firms were most deficient in managerial skills, nearly two-tenths (15\%) of the least successful firms had a similar experience. As the observed significance level of $.285>p=.05$, the relationship between managerial skills and success in small black-owned firms is not significant. This finding is not consistent with that of other studies, in which managerial skills are reported as one of the main success factors in small businesses.

Table 56

Comparison of Managerial Skills and Success in Black-owned $\underline{\text { Firms }} \underline{(\mathrm{N}} \equiv \underline{40)}$

\section{Success}

Most

Least

Managerial Skills

Not at all lacking

slightly lacking

Lacking

Very lacking

Most lacking

Total

Chi-Square

Pearson
Value

5.01818
Successful

$4(20 \%)$

4 (20\%)

$4(20 \%)$

$6(30 \%)$

$2 \underline{(10 \%)}$

$\underline{20}$

$D / F$

4
Successful

$0 \quad(0 \%)$

$4(20 \%)$

7 (35\%)

$6(30 \%)$

$3(15 \%)$

$\underline{20}$

Significance

.285

The relative deficiency of employee skills in the 
sampled firms is presented in Table 57. Whereas more than one-tenth (15\%) of the most successful firms reported that employee skills were not scarce, less than one tenth (5\%) of the least successful did so. In addition, about one-third (35\%) of the former stated that employee skills were scarce, compared to almost two-thirds (60\%) of the latter. The relationship between employee skills and success in small black-owned enterprises is not significant, as the observed significane level of $.296>p=.05$.

Table 57

Comparison of Employee Skills and Success in Black-owned Firms $(N \equiv \underline{40)}$

\section{Success}

Most

Least

Employee Skills

Not at all lacking

slightly lacking

Lacking

Very lacking

Most lacking

Total

Chi-Square

Pearson
Successful

3 (15\%)

7 (35\%)

7 (35\%)

$3(15 \%)$

음

$\underline{20}$

Value

4.91579
$D / F$

4
Successful

1 (5\%)

3 (15\%)

$12(60 \%)$

3 (15\%)

$1 \quad(5 \%)$

20 
firms is indicated in Table 58. More than one-third (35\%) of the most successful firms were not experiencing any shortage of entrepreneurial skills. In contrast, nearly a half (45\%) of the least successful firms reported that entrepreneurial skills were lacking; and one-tenth declared that the skills were most deficient. The relationship between entrepreneurial skills and success is not viewed as significant, as the observed significance level of $.067>p=.05$.

Table 58

Comparison of Entrepreneurial skills and success in Black-owned Firms $(N=40)$

\section{Success}

Most

Least

Entrepreneurial Skills

Not at all lacking

Slightly lacking

Lacking

Very lacking

Most lacking

Total

Chi-Square

Pearson

3.75000

value

3.75000
Successful

7 (35\%)

$2(10 \%)$

7 (35\%)

$3(15 \%)$

$1 \quad(5 \%)$

$\underline{20}$

$\mathrm{D} / \mathrm{F}$

4
Successful

$0 \quad(0 \%)$

$4(20 \%)$

$9(45 \%)$

$5(25 \%)$

2. $(10 \%)$ $\underline{20}$

Significance

In summary, it has been established that the resources discussed in this section were lacking, in varying degrees, 
in both the most successful and the least successful small black firms in the sample. However, the deficiency was more pronounced in the least successful firms. The relationship between the factors and success in the firms was only significant for internal $R \& D$ and consultancy. The other factors were not significantly related to success. Thus the third null hypothesis is rejected as the relationship between two of the critical factors and success is significant

Testing of Fourth Nul1 Hypothesis

Crosstabulation is used to categorize the responses of the subjects to specific questions, and the Chi-Square to test the fourth null hypothesis which is: staff development is not one of the determinants of success in small black-owned enterprises.

The relationship between staff development and success in black-owned firms is presented in Table 59. Both the most successful and the least successful black-owned firms regarded staff development as related to success. One-tenth of the most successful firms considered the factor as significant, compared to more than two-fifths (43\%) of the least successful. However, whereas almost half (47\%) of the most successful firms regarded staff development as an extremely significant success factor, less than one-fifth (14\%) of the least successful did so. As the observed significance level of $.036<p=.05$, the relationship between staff development and success in small black-owned 
firms is significant.

Table 59

Comparison of Staff Development and Success in Black-owned Firms $(\mathbb{N} \equiv 40)$

Success

Most

Least

Staff Development

Successful

Successful

Not at all significant

$0 \quad(0 \%)$

$0 \quad(0 \%)$

slightly significant

- $(0 \%)$

$0 \quad(0 \%)$

Significant

$3(10 \%)$

$8(43 \%)$

Very significant

$8(43 \%)$

$8(43 \%)$

Extremely significant

2 $(47 \%)$

$4(14 \div)$

Total

$\underline{20}$

$\underline{20}$

Chi-Square

Value

$\mathrm{D} / \mathrm{F}$

Significance

Pearson

6.60000

2

.036

The relationship between staff training and success in the sampled firms is presented in Table 60. Whereas half of the most successful firms provided staff training for more than three years in the period 1985 to 1989 , only one-tenth of the least successful did so. In addition, less than half (45\%) of the most successful small entrepreneurs, compared to more than four-fifths (85\%) of the least successful, provided training opportunities for less than one year in the same period. More emphasis was placed on training in the most 
successful than in the least successful small black firms. The relationship between training and success is significant as the observed significance level of $.02029<p=.05$. Table 60

Comparison of staff Training and Success in Black-owned Firms $(N=40)$

Success

Most

Least

Staff Training

More than three years

One to three years

Less than one year

Total

Chi-Square

Pearson
Value

7.79487
Successful

10 (50\%)

1 (5\%)

9 $(45 \%)$

20

D/F

2
Successful

$2(10 \%)$

1 (5\%)

$17(85 \%)$

$\underline{20}$

Significance

.02029

The fourth null hypothesis is rejected as the relationship between staff development and success in the sampled firms has been found to be significant.

\section{Testing of Fifth Nul1 Hypothesis}

In this section of this study the fifth null hypothesis is tested, which is: Small black entrepreneurs are not aware of the role of staff development in the success of their firms.

Crosstabulation was employed to categorize the responses 
of the subjects to the question whether they were aware of the role of staff development in the success of their firms. The Chi-Square was used to examine the relationship between level of awareness and success in the sampled firms. Both the most successful and least successful small black-owned firms reported that they were aware of the contribution of staff development to success in their firms.

Table 61 shows the relationship between awareness of staff development (as a success factor) and success. Table 61

Comparison of the Awareness of Contribution of Staff Development (to success) and Success in Black-owned Firms $\underline{(N} \equiv \underline{40)}$

Success

Awareness of Contribution

of Staff Development

Not at all aware

Not very aware

Aware

Very aware

Extremely aware

Total

Chi-Square

Pearson
Value

7.25113
Most

Successful

$0 \quad(0 \%)$

$0 \quad(0 \%)$

5 (25\%)

$8(40 \%)$

Z $(35 \%)$

$\underline{20}$

$D / F$

3
Least

Successful

$0 \quad(0 \%)$

$2(10 \%)$

8 (40\%)

9 (45\%)

$1(5 \%)$

$\underline{20}$

Significance .064 
Table 61 shows that one-tenth of the least successful firms, compared to none of the most successful, were not very aware of the role of staff development in the success of their firms. However, whereas more than one-third (35\%) of the most successful firms were extremely aware of staff development as a success factor, less than one-tenth (5\%) of the least successful were so aware. As the observed significance level of $.064>p=.05$, the relationship between awareness (of staff development as a success factor) and success is not significant. Therefore, the fifth null hypothesis is not rejected.

\section{Testing of Sixth Null Hypothesis}

The sixth null hypothesis is tested in this section of this study. The sixth null hypothesis is: The leadership styles of small black entrepreneurs do not affect success in their firms.

Crosstabulation is utilized to categorize the responses of the most and least successful small black entrepreneurs to specific questions. The comparison of basic styles of leadership and success is shown in Table 62. Eighty percent of the most successful entrepreneurs exercised democratic leadership in the running of their enterprises in that their employees participated in the decision-making process. In comparison, the employees in the least successful firms participated in decision-making in half of the cases. In the other firms in both groups the entrepreneurs alone made 
decisions. The relationship between leadership styles and success in the sampled firms is considered marginally significant, as the observed significance level of .046 $<\mathrm{p}=.05$.

Table 62

Comparison of Styles of Leadership and Success in Black-owned Firms $(N \equiv \underline{40)}$

\section{Success}

Most

Least

Styles of Leadership

Owner and workers make decisions

Owner alone makes decisions

Total

Chi-Square

Pearson

3.95604
Successful

$16(80 \%)$

$4(20 \%)$

$\underline{20}$

$D / F$

1
Successful

$10(50 \%)$

$10(50 \%)$

$\underline{20}$

Significance .046

The sixth null hypothesis is rejected as the relationship between styles of leadership and success is significant.

\section{Testing of the Seventh Null Hypothesis}

Crosstabulation and the Chi-Square test are utilized to examine the seventh null hypothesis in this study, which is: There is no relationship between HRD skills and success in small black-owned firms.

Table 63 presents the Chi-Square test of the 
relationship between fourteen selected HRD skills and success in small black-owned firms. Business activities are sometimes used as a framework within which to deliver instruction in training programs, eg. loan packaging, exporting etc. Table 63 indicates that about two-thirds (65\%) of the most successful entrepreneurs possessed the requisite skills in determining projects suitable for instructional development. In contrast, all the least successful firms were deficient in the particular skills. As the observed significance level of $.000<\mathrm{p}=.01$, the relationship between the skills in determining projects appropriate for instruction and success is significant.

For the effective formulation of staff development programs, the trainer needs to develop a profile of the learner, in which his or her basic characteristics are described. Table 63 illustrates that three quarters of the most successful entrepreneurs had the skills in evaluating the characteristics of employees who were engaged in learning projects within the firms. In comparison, only a fraction (5\%) of the least successful entrepreneurs had those skills at their disposal. As the observed significance level of .000 $<\mathrm{p}=.01$, the relationship between the skills in assessing learner characteristics and success in black-owned firms is significant. 
Table 63

Comparison of Selected Human Resource Development (HRD)

Skills and success in Black-owned Firms (N $\equiv 40)$

Success

Most Least

Successful Successful

Yes $\%$ No $\%$ Yes $\%$ No $\%$ Chi-Sq. DF Sig.

$\begin{array}{lllllllllll}\text { Determining Projects } 13 & 65 & 7 & 35 & 0 & 0 & 20 & 100 & 19.25 & 1 & .000\end{array}$

Assessing learner $\begin{array}{lllllllllll}15 & 75 & 5 & 25 & 1 & 5 & 19 & 95 & 20.41 & 1 & .000\end{array}$

$\begin{array}{llllllllllllll}\text { Analysing jobs } & 9 & 45 & 11 & 55 & 0 & 0 & 20 & 100 & 11.61 & 1 & .000\end{array}$

Writing statements

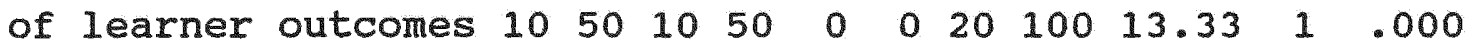
Analysing learning

environments

Learner outcomes

Instr. strategies

Learner activities

Instr. resources

Evaluating instruct.

Creating courses

Planning projects

Communication Skills

Interp. behavior $\begin{array}{lllllllllll}8 & 40 & 12 & 60 & 1 & 5 & 19 & 95 & 7.02 & 1 & .008\end{array}$

$\begin{array}{lllllllllll}12 & 60 & 8 & 40 & 0 & 0 & 20 & 100 & 17.14 & 1 & .000\end{array}$

$\begin{array}{lllllllllll}8 & 40 & 12 & 60 & 1 & 5 & 19 & 95 & 7.02 & 1 & .008\end{array}$

$\begin{array}{lllllllllll}11 & 55 & 9 & 45 & 1 & 5 & 19 & 95 & 11.90 & 1 & .000\end{array}$

$\begin{array}{lllllllllll}7 & 35 & 13 & 65 & 1 & 5 & 19 & 95 & 5.62 & 1 & .017\end{array}$

$\begin{array}{lllllllllll}0 & 100 & 0 & 0 & 4 & 20 & 16 & 80 & 26.66 & 1 & .000\end{array}$

$\begin{array}{lllllllllll}8 & 40 & 12 & 60 & 1 & 5 & 19 & 95 & 7.02 & 1 & .008\end{array}$

$\begin{array}{llllllllllll}7 & 35 & 13 & 65 & 0 & 0 & 20 & 100 & 8.48 & 1 & .003\end{array}$

$\begin{array}{lllllllllll}19 & 95 & 1 & 5 & 3 & 15 & 17 & 85 & 25.85 & 1 & .000\end{array}$

$\begin{array}{llllllllllll}17 & 85 & 3 & 15 & 2 & 10 & 18 & 90 & 22.55 & 1 & .000\end{array}$

An efficient training department should possess the 
requisite skills in job analysis and task analysis. Table 63 indicates that whereas nearly a half (45\%) of the most successful entrepreneurs were able to analyse the structural characteristics of jobs and tasks, none of the least successful had such skills. As the observed significance level of $.000<p=.01$, the relationship between the skills in analysing the characteristics of jobs and success is significant.

The trainer should have the skills to describe the expected outcomes of staff development. As illustrated in Table 63, half of the most successful entrepreneurs had the skills in writing statements of learner outcomes, whereas none of the least successful possessed those skills. As the observed significance level of $.000<p=.01$, the relationship between the skills in writing statements of learner outcomes and success is significant.

The trainer should possess the skills in identifying and describing the resources available for staff development within the firm. Table 63 reveals that whereas two-fifths of the most successful entrepreneurs had the skills in analysing learning environments, less than one-tenth (5\%) of the least successful were so equipped. As the observed significance level of $.008<p=.01$, the relationship between the skills in analysing the characteristics of the learning environment and success is significant.

The skills in sequencing learner outcomes were present 
in the sampled firms as indicated in Table 63. Whereas three-fifths of the most successful entrepreneurs could sequence learner outcomes, none of the least successful had such skills. As the observed significance level of $.000<$ $\mathrm{p}=.01$, the relationship between the skills in sequencing learner outcomes and success in the sample is significant. Table 63 shows that two-fifths of the most successful entrepreneurs, compared to less than one-tenth (5\%) of the least successful, possessed the skills in specifying instructional strategies in their staff development programs. As the observed significance level of $.008<p=.01$, the relationship between the skills in specifying instructional strategies and success is significant.

Table 63 indicates that whereas over half (55\%) of the most successful entrepreneurs had the skills in sequencing learner activities in their staff development programs, only a minority $(5 \%)$ of the least successful were so equipped. As the observed significance level of $.000<p=.01$, the relationship between the skills in sequencing learner activities and success is significant.

Table 63 also illustrates that whereas more than one-third (35\%) of the most successful entrepreneurs had the skills in determining resources suitable for specific instructional events, less than one-tenth (5\%) of the least successful were so endowed. As the observed significance level of $.017<p=.05$, the relationship between the skills 
in determining instructional resources and success is significant.

All the most successful entrepreneurs possessed the skills in evaluating instruction, compared to one-fifth of the least successful. As the observed significance level of $.000<\mathrm{p}=.01$, the relationship between the skills in evaluating instruction and success is significant.

The job of the trainer also includes the formulation of courses, the development of learning packages, and the institution of management systems for workshops. The trainer needs to specify the goals, content, and the criteria for the evaluation of staff development program. The creation of materials for the participants, and guidelines for the workshop manager are important aspects of the staff development function. Table 63 illustrates that whereas two-fifths of the most successful entrepreneurs had the necessary skills in creating courses, learning packages and management systems for workshops in their HRD programs, less than one-tenth $(5 \%)$ of the least successful were so endowed. As the observed significance level of $.008<\mathrm{p}=.01$, the relationship between the skills in creating courses and success is significant.

Table 63 shows that more than one-third (35\%) of the most successful entrepreneurs possessed the skills in planning and monitoring staff development programs, whereas none of the least successful had any of those skills. As the 
observed significance level of $.003<p=.01$, the relationship between the skills in planning and monitoring instructional development and success is significant.

As presented in Table 63, whereas nearly all (95\%) of the most successful entrepreneurs were able to communicate effectively in different forms, less than one-fifth (15\%) of the least successful could do so. As the observed significance level of $.000<p=.01$, the relationship between the skills in communication and success is significant.

Whereas more than four-fifths $(85 \%)$ of the most successful entrepreneurs had the requisite skills in interpersonal behavior, only one-tenth of the least successful were so equipped. As the observed significance level of $.000<p=.01$, the relationship between the skills in interpersonal behavior and success is significant.

The relationship between all of the selected HRD skills and success in the sampled firms is significant. Thus, the seventh null hypothesis is rejected. 


\section{CHAPTER FIVE. SUMMARY AND CONCLUSIONS}

Introduction

In this the final chapter of this study, the following are presented: a summary of the study, a discussion of the findings in light of the study's theoretical framework, the specific conclusions reached, and the recommendations for further research.

\section{Summary of the study}

In recent years the small business sector in the United states has made a significant contribution to national development. Consequently, the federal government introduced various programs to promote the growth and development of small businesses. Despite significant federal assistance, the mortality rate among small enterprises has continued at a relatively high level.

Although no comprehensive management theory exists to analyse the problems of small businesses, various studies have identified certain causes of small business failures. The latter include a deficiency of credit, modern equipment, internal $R \& D$, and the lack of entrepreneurial, managerial and employee skills.

other studies have examined the success factors in small businesses such as entrepreneurial behavior, managerial skills, interpersonal skills, creativity, innovation, motivation, communication skills, and the personality characteristics of the entrepreneur. These success factors 
are all related to the human resources within the enterprise. As small entrepreneurs lack extensive control over the supply of financial and physical resources to the firm, to achieve success they have to depend increasingly on maximizing the efficiency of the human resources within the firm. In this process, the availability of human resource development skills is critical for staff development.

The problem examined in this study was the characteristics of successful small black-owned firms in Dade County, Florida. The purpose of this study was to identify the characteristics of the successful small black-owned enterprises, focusing on the relationship between selected critical factors and success.

The review of the literature sought to answer seven major questions surrounding the problem in this study. Those questions generated seven null hypotheses which constituted the framework of the study.

A descriptive and correlational research method was selected for this study, which included two phases. The first phase was a base data survey of a sample of the target population of small black entrepreneurs in Dade County, Florida. The survey provided data concerning the demographic characteristics of the target population, and tested the first null hypothesis discussed later in this chapter. The base data were collected by means of a questionnaire. Most successful and least successful small black entrepreneurs 
were identified, and a random sample comprising twenty representatives from each group was selected. This sample was the base of the second phase of this study, which was a guided interview designed to generate quantifiable data to test the remaining six null hypotheses in this study.

In Phase One (the base data survey) of this study, percentages and frequency counts were utilized to describe and analyse the numeric and categorical variables. The Chi-Square was used to assess the relationship between the categorical variables and success, and the t-test to assess the differences between the most and the least successful small black-owned firms on the numeric variables.

In Phase Two (the interview study), percentages and frequency counts were utilized to describe the data collected for the sample of twenty most successful and twenty least successful small black entrepreneurs. The Chi-Square was utilized to examine the relationships between the categorical variables and success in small black-owned firms. The $t$-test was used to assess the differences between the two groups in respect to the six remaining null hypotheses in this study.

The major findings of this study in terms of the hypotheses tested and questions answered are:

1. The first null hypothesis was rejected as the characteristics for success were not the same for the most successful and the least successful small black-owned firms.

2. The second null hypothesis was rejected as the factors 
essential for success were not identical in the most successful and the least successful small black-owned enterprises.

3. The third null hypothesis was rejected as a significant relationship exists between selected critical business factors and success.

4. The fourth null hypothesis was rejected as the relationship between staff development and success was found to be significant.

5. The fifth null hypothesis was not rejected as the relationship between awareness (of staff development as a success factor) and success was not significant.

6. The sixth null hypothesis was rejected as the relationship between leadership styles and success was determined to be significant.

7. The seventh null hypothesis was rejected as the relationship between selected HRD skills and success was significant.

\section{Discussion}

In this section the findings are further discussed in light of the literature review presented in Chapter Two. The research questions are used to provide structure and flow to the discussion which embraces the principal conclusions drawn from the findings, as well as their practical implications. The primary concern of this study was the nature of the characteristics of the successful small black-owned firms in 
Dade County, Florida. The seven research questions were examined in order to address the problem in this study.

\section{First Research Question}

First research question: What are the general characteristics of small black-owned firms?

First null hypothesis: The characteristics for success are the same for all small black-owned firms.

Like other business persons, success in operating the business is the major objective of the small black entrepreneur. Success has been the focus of many research studies due to the high mortality rate among small firms. Consequently, various success factors have been identified (Thomas, 1988), in order to provide guidelines for the successful operation of small firms.

In this study it has been determined that the selected success factors were not identical for the sampled firms. The relationship between duration of present business and success was significant. The two groups of respondents the most successful and the least successful small black entrepreneurs- showed differences in their rates of success over time. Nearly two-thirds $(61.2 \%)$ of those in business for five to seven years were least successful, whereas more than four-fifths $(85.5 \%)$ of those in business for more than ten years were most successful. Apparently the success rate was greater for the small black-owned business the longer the period it was in operation. 
In this study form of business organization (sole proprietorship, partnership, corporation) was not identified as a success factor for small black-owned enterprises. This finding is supported in the literature as there is no evidence that any business structure is any more successful than another.

Major business activity was determined to be associated to success, as the relationship between both factors was significant. The sampled firms had as their major business activities the retail trades, services, the professions and construction. The majority of the firms in these activities were most successful. More than four-fifths $(86.7 \%)$ of the firms in construction, over half $(52.6 \%)$ in retail, more than two-thirds (67\%) in services and nearly two-thirds (65.7\%) of those in the professions were most successful.

Net profit was identified as a success factor, as its relationship to success in the sampled firms was significant. There were significant differences in the amounts of net profit earned by the most and least successful firms in the sample. Nearly all of the firms which failed to make a net profit (97\%) were least successful. In comparison, more than nine-tenths of the firms earning a net profit from $\$ 50,000$ to $\$ 150,000$ in 1989 were most successful.

There were significant differences in the number of full-time employees engaged by the most and least successful firms, and in the number of years a net profit was earned 
during the period 1985 to 1989 . However, there was no significant difference between the two groups concerning the number of part-time workers employed.

\section{Second Research Question}

Second research question: What critical factors are essential for success in small black-owned businesses?

Second null hypothesis: The factors essential for success are identical in all small black-owned firms.

The majority of the selected success factors were not determined to be identical in the sampled enterprises. There was no significant difference between the groups on training, flexible informal control system, close unstructured communication system, environmental characteristics, top management involvement, and maintenance of a long range orientation. However, differenes between the most and least successful firms were found in respect to:

i. Education

ii. Entrepreneur as final decision-maker

iii. Entrepreneurial behavior

iv. Innovation

v. Creativity

vi. Managerial competence

vii. Managerial skilis

viii. Interpersonal skills

ix. Skills of key employees

x. Setting of priorities from the early phase 
The success factors which were not identical for both the most and least successful small black entrepreneurs were more characteristic of the former than of the latter firms. An examination of these factors indicates that they are closely related to the human resources within the firm over which the small entrepreneur can exercise some direct control, unlike the other two factors - financial resources and physical resources - over which he has little control, if any (Nadler, 1986). It is likely that some of the firms were most successful because they utilized effectively the human resources at their disposal.

\section{Third Research Question}

Third research question: Is there any relationship between the amount of critical factors and success in small black-owned firms?

Third null hypothesis: There is no relationship between the amount of selected critical factors and success in small black-owned firms.

The selected critical factors were deficient in both the most and least successful small black-owned firms in the sample. This inadequacy was more significant in the latter than in the former firms. The relationship between the selected critical factors and success was not significant, except for internal $R$ \& $D$ and consultancy skills. The critical factors which were not related to success were: venture and reserve capital, systematic financial and 
strategic planning, modern equipment, departmentation skills, managerial skills, employee skills, and entrepreneurial skills. These findings were not expected, as the particular critical factors were determined in other studies as vital to the success and growth of small enterprises in general.

Olson (1987) reported that during the growth phase various functional departments are usually established within the small enterprise; and the introduction of work routines necessitates a pool of specialized skills. Thomas (1988) noted that managerial, employee and entrepreneurial skills were crucial to the success of small black-owned enterprises. Thomas (1988) also stated that access to operating capital was important for success in black-owned firms. Chang (1986) pointed to the scarcity of venture and reserve capital as a significant reason why many small firms failed.

Systematic financial/strategic planning and modern equipment are two of the determinants of success in small enterprises (Udel, 1978). Departmentation skills also contribute to the success of small enterprises (Olson, 1987). The scarcity of the selected critical factors in the sampled firms is not surprising. The private banking system in the United States has become very conservative in recent years, and has reduced its lending to the small black business sector (Dingle, 1986). The majority of the sampled firms were sole proprietorships, employing between one and two workers. The small size of the enterprises has not 
necessitated the creation of separate departments. Therefore, the need for departmentation skills within the average small black-owned enterprises has not been significant. The small entrepreneur cannot devote sufficient time to such important functions as systematic financial and strategic planning. The shortage of venture/reseve capital has contributed to the inadequacy of modern equipment in small black-owned firms.

\section{Fourth Research Question}

Fourth research question: Is staff development one of the determinants of success in small black-owned firms? Fourth null hypothesis: Staff development is not one of the determinants of success in small black-owned firms.

Staff development was found to be one of the determinants of success in the sampled firms, as the relationship between the two variables was significant. As the small entrepreneur possesses little control over the availability of financial and physical resources (Nadler, 1986), he has to rely heavily on the efficiency of the human resources in order to realize growth and success in the American economy which in recent years has become very complex and competitive. Thomas (1988) reported that training and education were prerequisites for success in black-owned firms. 


\section{Fifth Research Question}

Fifth research question: Are small black entrepreneurs aware of the role of staff development in the success of their firms?

Fifth null hypothesis: Small black entrepreneurs are not aware of the role of staff development in the success of their firms.

Small black entrepreneurs in general were not aware that staff development was important for success. Actually, whereas a little more than one-third (35\%) of the most successful firms were extremely conscious of staff development as a success factor, less than one-tenth of the least successful were so informed. The relationship between awareness and success was generally not significant. It seems that the most successful small black entrepreneurs were those who sought inclusion on the minority vendor lists of state and local governments, as well as other organizations. Consequently, they would be more aware of success factors such as staff development.

Probably the small business development agencies in Dade County have not been adequately aggressive in promoting their staff development programs in the black small business sector. This situation may very well explain the low level of awareness of the value of staff development in small black-owned businesses. 


\section{Sixth Research Question}

Sixth research question: Does the leadership styles of small black entrepreneurs affect success in their firms? Sixth null hypothesis: The leadership styles of small black entrepreneurs do not affect success in their firms.

The leadership styles of small black entrepreneurs affect the success of the firms. Four-fifths of the most successful firms had democratic leadership in that the employees participated in decision-making, compared to only half of the least successful firms. Also half of the least successful firms had owners who alone made decisions, compared to just one-fifth of the most successful. It is likely that the small black entrepreneur has to adopt a leadership style that allows the maximum participation of the employees in the running of the business in order to ensure success.

\section{Seventh Research Question}

Seventh research question: Is there any relationship between HRD skills and success in small black-owned firms?

Seventh null hypothesis: There is no relationship between HRD skills and success in small black-owned firms.

All the selected HRD skills in this study were found to be significantly related to success in black-owned firms. Both the most and least successful firms were deficient in respect to the selected HRD skills. The inadequacy was more pronounced in the least successful firms. Probably the most 
successful firms were more conscious of the need for human resource development in promoting success. Thus HRD skills would have been acquired to improve staff development efforts.

\section{Conclusions}

In this study information on a sample of small black-owned firms in Dade County, Florida, was collected and analysed in a basic survey and interview study. Based on the findings in the two phases of this study, the following conclusions have been made:

1. The major characteristics of successful small black-owned firms are:

a. The sole proprietorship is the main form of business organization among successful small black-owned firms.

b. Their major business activities are the retail trades and services.

c. Most of them $(63.2 \%)$ make a net profit of less than $\$ 50,000$.

d. The majority (76.1\%) of small black entrepreneurs make a net profit at least three in any five year period.

e. Small black entrepreneurs in Dade County, Florida, engage between one and two full-time employees.

f. The majority of small black-owned firms do not engage part-time employees.

2. Success factors are not identical for all small black-owned firms. 
3. The relationship between internal research and development ( $R \& D$ ) and success is significant.

4. The relationship between consultancy services and success in small black-owned businesses is significant.

5. The majority of small black-owned firms are relatively deficient in critical factors.

6. The relationship between staff development and success in small black-owned firms is significant.

7. The majority of small black entrepreneurs are not extremely aware of the value of staff development to the success of their firms.

8. The relationship between leadership styles and success is significant in small black-owned enterprises

9. The relationship between HRD skills and success is significant in small black-owned firms.

\section{Recommendations for Further Research}

This study is an exploratory effort to define the characteristics of the successful small black entrepreneurs in Dade County, Florida. The following recommendations are made for further research:

1. Experimental studies need to be carried out to further analyse the relationship between HRD skills and success in black-owned firms as the findings of this study should be treated as preliminary.

2. To confirm or disconfirm the findings as, unlike this study, other studies have reported a significant relationship 
between the following factors and success in small enterprises: venture and reserve capital, systematic financial and strategic planning, modern equipment, departmentation, managerial,employee and entrepreneurial skills.

3. To further assess the relationship between awareness of staff development (as a success factor) and success in small black-owned firms.

4. To analyse the relationship between leadership styles and success in black-owned firms as the relationship in this study was determined to be marginally significant. 


\section{LIST OF APPENDIX}

Appendix

A

B

c

D

E
Title

Schedule of Activities for the Proposed

Study

Form Letter to the Sample for the

Questionnaire Study

Letter of Endorsement from the Director of

the Miami/Fort Lauderdale Minority Business

Development Center

Small Business Questionnaire

Interview schedule 
APPENDIX A

SCHEDULE OF ACTIVITIES FOR PROPOSED STUDY

Activities

Dates

Phase One

1. Pilot Study

$1 / 15 / 91-2 / 15 / 91$

2. Selection of subjects

$2 / 16 / 91-2 / 28 / 91$

3. Data Collection

$3 / 1 / 91-5 / 15 / 91$

4. Data Analysis

$5 / 16 / 91-5 / 31 / 91$

5. Interpretation

Phase Two

$6 / 1 / 91-6 / 15 / 91$

6. Construction of Interview Guide

$6 / 16 / 91-6 / 30 / 91$

7. Pretesting Interview Guide

$7 / 1 / 91-7 / 15 / 91$

8. Selection of Subjects

$7 / 16 / 91-7 / 31 / 91$

9. Conduction of

Interviews

$8 / 1 / 91-8 / 15 / 91$

10. Data Analysis

$8 / 16 / 91-8 / 31 / 91$

11. Interpretation

$9 / 1 / 91-9 / 15 / 91$

12. Final Report

$9 / 16 / 91-10 / 31 / 91$ 
APPENDIX B

Dear

RE : Small Business Survey

I am a doctoral candidate in the Adult

Education and Human Resource Development Program at Florida International University. I am currently conducting a study for my dissertation. The purpose of the study is to examine the characteristics of successful small black-owned firms in Dade county, Florida.

I am seeking your cooperation in this study. Would you take a few minutes to complete the enclosed survey and return it in the stamped, self-addressed envelope I have enclosed by , 1990. All information will be treated in strict confidence, and will be used for statistical analysis only. A high rate of return of the survey is vital to the findings of the study. Therefore, your response is very important, and would be much appreciated.

If you like, I will share with you the results of the study. If you have any questions, do not hesitate to contact me at $305-5599012$.

Thank you for your time and interest in this study. I look forward to receiving your completed survey. Yours truly, 
APPENDIX C

Miami/Ft. Lauderdale Minority

Business Development Center

funded by: U.S. Department of Commerce

Minority Business Development Agency

February 1, 1991

Dear Survey Respondent:

The Miami/Ft. Lauderdale MBDC encourages you to complete the attached survey/questionnaire prepared by $\mathrm{Mr}$. Dickson. The data gathered from all completed/returned questionnaires will allow Mr. to present a study, of black-owned businesses in Dade County, that may serve as the basis for future economic development initiatives.

The Miami/Ft. Lauderdale MBDC fully supports the efforts of Mr. Dickson and it hopes that you will recognize the potential benefits of this study by collaborating with your responses.

sincerely yours,

Francis J. Lamprea

Executive Director

FJL/rrn

Kendal Square Associates

1200 N.W. 78th Avanue, Suite 301

Miami, FL 33126, 305-591-7355. 


\section{APPENDIX D}

\section{SMALL BUSINESS QUESTIONNAIRE}

Please complete each item. Do not sign the form. All information supplied is strictly confidential, and will be used for statistical analysis only.

Directions: For each item listed below, please put a check in the appropriate space to indicate your answer. Profit is taken to mean net profit after allocations to reserves and taxation.

1. How long have you been conducting your present business (if less than five years, do not answer the remaining questions)?

Less than 5 years

5 - 7 years

7 - 10 years

More than 10 years

2. What form of business organization is your firm? Sole Proprietorship. Partnership Corporation

3. Please check one of the following categories to indicate your major business activity:

_Construction (General contractor, painting, carpentry etc.).

_Manufacturing

_Transportation (Truckers, movers, etc.). Wholesale

_Retail (service station, restaurant, bar etc.). 
Agriculture (afforestation, landscaping, fisheries etc.).

_Financial (real estate, bank, savings and loan etc.). _Services (beauty salon, barber, garage, motel etc.). -Professional (Physician, dentist, attorney, engineer).

4. How many employees do you have full and part-time, including yourself? full-time_part-time

5. How many years has your firm made a net profit (after allocations for investment and taxation) during the previous five years? Check each of the following years when a net profit was made: —1985_1986_1987_1988_1989

6. How much net profit did your firm make for the year ending December 31, 1989?

None
Under $\$ 50,000$
$\$ 50,001-\$ 100,000$
$\$ 101,000-\$ 150,000$
$\$ 150,001-\$ 200,000$
$\$ 200,001-\$ 250,000$
$\$ 250,001-\$ 300,000$
$\$ 300,001-\$ 350,000$
$\$ 350,001-\$ 400,000$
$\$ 400,001-\$ 450,000$
$\$ 450,001-\$ 500,000$
Over $\$ 500,00$


APPENDIX E

\section{INTERVIEW SCHEDULE}

A Study of the Characteristics of Successful Small Black-owned Enterprises in Dade County,

Florida

Introduce yourself. Create a comfortable, trusting environment before commencing the interview. Be cognizant of the fact that the majority of the interviewees will not be experienced in formal interviewing, and that many of the terms used will be strange to them. Conduct the interview carefully, recording any complexity and uncertainty. Provide the interviewee with any relevant assistance in order that he/she can respond appropriately to the questions.

Indicate the purpose of the interview by stating something like...

"I am trying to find out the characteristics of the successful small black-owned firms in Dade County, Florida. Many small black entrepreneurs are successful, but for different reasons- and to varying degrees.

"I'm interested in talking to business people like yourself to find out the factors which have helped them to be successful during the last five years.

"When I talk about "success" I am not just referring to the survival of your firm during the previous five years. I mean 
that your firm might have done very well, or not so very well, or might have just covered its costs of operations (including investment).

Maybe you took certain actions which caused your business to be successful - improving old ones or introducing new ones. or perhaps certain events in the economy assisted your business.

"Try to think about the last five years. I want to find out what helped to ensure your business success. You may point out any of the items on the list I will present to you, whether or not you think it is significant.

"I wish to make a list of the success factors for small black-owned firms in Dade County, because they are not widely known. Another question which I would like to answer is the important factors that are lacking in small black-owned firms that are barely successful. This explains why I want you to answer fully the questions which I will ask you.

"Try to think of the manner in which you run your business. I am interested in finding out if the way you operated your business has affected the efficiency of your workers. You may give me any information you think is important.

"I will need information on the training of workers in your firm, as I intend to find out if staff development is one of the ways to realise success in small black-owned enterprisess, and if so, to what extent. 
"I will be checking to see if small black business persons are aware of the role that staff development can play in the success of their businesses. Also important is the extent to which skills to develop staff training programs are found in small black-owned firms.

"As you talk to me, I will be recording the interview by the use of this device (show tape recorder). I find that often important information is not written down during an interview, and that reports prepared later on do not include important points. This is sometimes caused by a lapse of memory after the interview. By using this recorder, I will be able to record all the points made in the discussion. "To help you to remember, please look over this list of questions (show list). I don't expect you to remember everything immediately. I will, for this reason, ask additional questions to assist your memory. Point out that it usually takes about $3-5$ seconds for one to answer a difficult question, and that it is okay to take some time. Do not interrupt the person's response in order to ask further questions, unless it is evident that the interviewee is far off track. Do not dispute the interviewee's decisions and opinions, but certainly do at times make one or more attempts to check his understanding of the question, or to clarify their response. Note any doubts you have about the accuracy or relevance of the answers you get. 
Critical Factors Essential For Success In Small Businesses (Question \#1 on Data sheet).

Note : Now we are interested in finding out the critical success factors in small black-owned enterprises. These factors are often not obvious. You will need to think carefully about possible success factors in your business.

When you are convinced that the interviewee has identified and rated from the list all possible success factors, say something like this....

Alright, thank you. You have listed and rated all the success factors you know. If you think of any other while we are talking, please do mention them.

Relationship Between selected Critical Factors and success In Smal1 Black-owned Firms (ouestion \#2 on Data Sheet).

To initiate the discussion on this topic in the interview, say something like this....

"The presence of certain factors is required for the success of small firms. If they are absent, the firms may only be barely successful. It is important to identify these factors so that needed actions might be taken to make the small firm successful.

" Here is a list of critical factors which might ensure the success rate of small busineesses. Identify and rate those you consider related to the success of small firms." Show the list of critical factors which should be present in successful small enterprises. The interviewee 
should then rate the factors on the five-point scale provided.

Staff Development As A Determinant of Success couestion \#3 On Data sheet).

To commence discussion on this topic, say something like this....

"Staff training requires that certain skills be present in an organization. These skills are usually related to what the manager is trying to achieve now and in the future. These skills are very important in a small business which lacks control over the supply of capital and modern equipment; and has to depend very much on the use of its workers for its effectiveness.

"Do you consider staff development as one of those factors affecting success in your business? Rate your response using the five-point scale provided. Awareness of The Role of staff Development couestion \#4 on Data sheet).

To begin this subject in the interview, make a statement like this....

"The small business person often does'nt have much resources in his business. As he is concerned about the success of the firm, he should know the factors that help the growth and success of his business. Do you know that staff training promotes the success of your business? Please rate your answer using the five-piont scale provided. 
Leadership Styles and Success (Question \#5 on Data Sheet).

To commence the discussion on this topic in the interview, make a remark like...

"Whenever we run a business, we do so in a particular manner. Sometimes the manager allows the workers to participate in the making of decisions affacting the business. At other times, the manager permits the workers themselves to make decisions concerning various business matters. At the other extreme, the manager alone makes all the business decisions.

Explain fully to the interviewee the main distinctions between the three leadership styles. Ask him/her to describe how he/she takes decisions in his/her business. Then ask him/her to say if the leadership style used has affected his/her attitude to staff training, and if so, how. Finally, ask the interviewee to rate the extent to which he/she promotes staff training in the firm.

Human Resource Development Skills and Success(ouection \#6 On Data sheet).

To initiate discussion on this topic, make a statement like this...

"Staff development skills are those that are required to organize, conduct, and assess training programs within a firm. Some firms possess these skills to ensure that their training programs satisfy the needs of their employees. Which of these skills are now present in your firm? 
Show the list of staff development skills to the interviewee, explaining each one in order to ensure that the correct responses are provided. 
A STUDY OF THE CHARACTERISTICS OF THE SUCCESSFUL SMALL

BLACK-OWNED ENTERPRISES IN DADE COUNTY, FLORIDA

Data sheet

Note: Record the time

the interview began

Interview

Code Data

Notes

Name:

(Name of Person Being Interviewed)

Interviewer:

1. What factors are essential for success

in your business? Rate the following

factors using this scale:

5 - Most Essential

4 - Very Essential

3 - Essential

2 - Slightly Essential

1 - Not At All Essential

Training

Education

Development

Flexible, informal control system

close, unstructured communication

system

Entrepreneur as final decision-

maker 
Entrepreneurial behavior

Innovation

Creativity

Managerial competence

_Managerial skills

Interpersonal skills

Environmental characteristics

Top management involvement

Skills of key employees

setting of priorities from

early phase

Maintenance of a long range

orientation

2. What critical success factors are lacking in small black-owned businesses?

Rate the following factors using this scale:

5 - Most Lacking

4 - Very Lacking

3 - Lacking

2 - Slightly Lacking

1 - Not at all lacking

Venture and reserve

capital

Systematic financial and strategic

planning

Internal $R \& D$ 
Modern equipment

Availability of consultants

Departmentation

Managerial skills

Employee skills

3. Is staff development one of the

determinants of success in your firm?

_Yes No

If yes, rate your response on the following scale:

5 - Extremely Significant.

4 - Very significant.

3 - Significant.

2 - Not Very Significant.

1 - Not At All Significant.

How much job-related training have

you provided your employees during

the past five years?

More than three years

- one to three years

Less than one year

4. Have you been aware of

the role of staff development

in the success of your firm? Yes_No -

Rate your response on the

following scale:

5 - Extremely Aware. 
4 - Very Aware.

3 - Aware.

2 - Not Very Aware.

1 - Not At All Aware.

5. What is your basic style of

leadership?

Owner and workers make decisions Workers make most major decisions

Owner alone makes business decisions

Does your leadership style

affect success in your firm? Yes__ No

If yes, in what way? Positively_Negatively

If positively, in what form(s) do you promote

staff development?

_on-the-job training. Formal training within the firm.

Formal training in specified institutions.

6. Do you regard the following staff training skills as important for success in your firm?

Determine projects appropriate

for instructional development. Yes No Assess learner characteristics. Yes No Analyse the structural characterictics 
of jobs, tasks, and content.

Yes No

Write statements of learner

outcomes.

Yes No

Analyse characteristics of

learning environment.

Yes No

Sequence learner outcomes.

Yes No

Specify instructional

strategies.

Yes No

Sequence learner activities.

Yes No

Determine instructional

resources appropriate to

instructional activities.

Yes No

Evaluate instruction.

Yes No

Create courses, learning

package, and workshop

management system.

Yes NO

Plan and monitor instruct-

ional development projects

Yes No

Communicate effectively in

visual, oral and written

form.

Yes No

Demonstrate appropriate

interpersona1, group process

and consulting behavior.

Yes No 


\section{REFERENCES}

Appleby, R.C. (1982). Modern Business Administration. Massachusetts: Pitman Publishing Inc.

Black enterprises in Dade County, 1987. Metropolitan Dade County, Florida: Metro-Dade Office of Black Affairs. Brockhaus, R. (1980). Risk taking propensity of entrepreneurs. Academy of Management Journal, 3 , 509-520.

Budke, W., \& Kerka, S.(1988). Human Performance Technology. Eric Clearinghouse on Adult, Career, and Vocational Education, Columbus, Ohio.

Carter, J. S. (1978). Success and its determinants: A study of selected firms operating under the Small Business Administration's 8(a) Program (For the Promotion of Business Owned and Controlled by Socially and Economically Disadvantaged Persons). (Doctoral dissertation, The American University, 1974). Dissertation Abstracts International, 35, 1798A. Chaganti, R., Chaganti, R. (1983). A profile of profitable and not so profitable small businesses. Journal of Smal1 Business Management, 21, 45-50. Chang, C. (1986). A study of problems identified by Asian owner-operators of small businesses in California. (Doctoral dissertation, United States International University, 1986). Dissertation Abstracts International. 47. 1805A. 
Chilton, K. W. (1984). What should government do for small business? Journal of Smal1 Business Management, 22, 1-3. Comprehensive annual financial report, 1987. Metropolitan Dade County, Florida : Finance Department. d'Amboise, G. \& Muldowney, M. (1988). Management theory of smal1 business. Academy of Management Review, 13. $226-240$

Demas, G. L., Welsh, R. J. (1986). Profile of black-owned businesses, Dade County, 1982. Research Division, Metro-Dade County Planning Department. Dickson, D. L. (1983). A quantitative training needs assessment of the small business community of Grand Junction, California. (Doctoral dissertation, University of Northern Colorado, 1983). Dissertation Abstracts International, 44, $1871 \mathrm{~A}$. Dingle, D. T. (1986). Seeking an agenda for economic growth. Black Enterprise, pp. 201-8.

Donald, M. N. (1960). Implications of nonresponse for the interpretation of mail questionnaire data. Public Opinion ouarterly, 24, 99-114.

Economic report of the president to the congress, January, 1987. (Report No. 40. 9: 987). Washington D.C: Government Printing office.

Economic report of the president to the congress, January, 1989. (Report No. 40.9: 989) Washington D.C.: Government Printing office. 
Evans, J. H., Evans, F. C. (1986). A small manufacturer's success story. Management Accounting, 68, 47-48. Fink, A., Kosecoff, J. (1985). How to conduct surveys: A step-by-step guide. Beverley Hills: SAGE Publications.

Fisseha, Y. (1982). Management characteristics, practices and performance in the small-scale manufacturing enterprise: Jamaican milieu. (Doctoral dissertation, Michigan state University, 1982). Dissertation Abstracts International, 43, 4015A.

Fowler, F. J. (1988). Survey research methods. Beverley Hills: Sage Publications Inc.

Gay, L. R. (1987). Educational research: competencies for analysis and application. Charles E. Merrill Publishing Company: Ohio.

Goad, T. W. (1981). Organization development and small business firms. (Doctoral dissertation, United States International University, 1980). Dissertation Abstracts International, 41, 730A.

Greenberg, B. (1987). Using microcomputers and mainframes for data analysis in the social sciences. Columbus: Merrill Publishing Company.

Hambrick, D. C., \& Crozier, L. M. (1985) Stumblers and stars in the management of rapid growth. Journal of Business Venturing, 1, 31-35. 
Holbek, J. (1975). Economic effectiveness of small manufacturing firms in the furniture industry of Norway. (Doctoral dissertation, Northwestern University, 1975). Dissertation Abstracts International, 36, 7546A.

Hope, J. C. (1983). A study of management tasks in business managed by owner-managers with implications for small business management skills. (Doctoral dissertation, Claremont Graduate School, 1983). Dissertation Abstracts International, 43, 3967A.

Howatt, J. (1978). An analysis of the investments of small business investment companies. (Doctoral Dissertation, University of Illinois at Urbana-Champaign, 1979). Dissertation Abstracts International, 40, 382A. Hylton, R. D. (1988). Meeting the challenges of corporate renewal. Black Enterprise, pp. 259-266.

Ibrahim, A. B., Goodwin, J. R. (1986). Perceived Causes of success in small business. American Journal of Small Business, 11, 41-50.

Kelly, I. (1984). Small business's big training needs. Training and Development Journal, 38, 35-42.

Kent, S. (1986). Business failures: Economic determinants and potential effects on the macroeconomy. (Doctoral dissertation, George Washington University, 1986). Dissertation Abstracts International, 47, 1429A. 
Khan, R., Roca, J. (1982). Recurring managerial problems in small business. American Journal of Small Business, $1(7), 50-58$.

Linsky, A. (1975). Stimulating response to mailed questionnaire: A review. Public opinion Quarterly, 39, 82-101.

Long, T. J., Convey, J., Chwalek, A. R. (1986). Completing dissertations in the behavioral sciences and education. Jossey-Bass Publishers: San Froncisco.

Metro-Dade Office of Black Affairs. (1987). Black Enterprises in Dade County, Third Edition.

Minks, L. (1980). Development of a conceptual framework for the analysis of the small retail business. (Doctoral dissertation, University of Northern Colorado, 1980). Dissertation Abstracts International, 41, 2682A. Nadler, L., \& Wiggs, G. D. (1986). Managing human resource development. San Francisco: Jossey-Bass. Nicholson, R. (1983). Managing emerging businesses. Managing, 3, 20-25.

olson, P. D. (1987). Entrepreneurship and management. Journal of Sma11 Business Management, 25, 7-13. Pecorella, P. A. (1978). Forecasting performance in organizations: An application of current-value human resources accounting. Final Report, Michigan University, Ann Arbor. 
Rimler, G. W., Humphreys, N. J. (1976). Successful delegation - a must for small business. Journal of Small Business Management. 14, 42-45.

Robinson, R. (1979). Forecasting and small business: A study of the strategic planning process. Journal of Small Business Management, 17, 19-27.

Rock, A. (1987). Strategy vs tactics from a venture capitalist. Harvard Business Review, 65, 63-67. Roitman, D. B., Emshoff, J. C., Robinson, R. (1984). College-based management and technical assistance for small business. Journal of Small Business Management, 22, 53-61.

Schilit, W. K. (1986). Guidelines for entrepreneurial success. Advanced Management Journal, 51, 44-48. Sexton, D., Bowman N. (1983). Determining entrepreneurial potential of students: Comparative psychological characteristics analysis. Academy of Management Proceedings, Dallas, 408, 412.

Staff. (1989, September 17). New MDCC branch hopes to give boost to minority businesses. Miami Herald, p. 2B. Staff. (1989, May 10). Minority firms grow. Sun Sentinel, p. 1 . Steiner, M., Solem, O. (1988). Factors for success in small manufacturing firms. Journal of Small Business Management, 26, 51-56. 
Thomas, H. (1988). Blacks and the economy of Florida (Report No. 87-048). Florida: The Black Business Investment Board.

Thomas, J 111, Evanson, R. V. An empirical investigation of association between financial ratio use and small business success. Journal of Business Finance and Accounting, 14, 555-571.

Udell, G. G., Baker, K. G. (1978). Manual for innovation evaluation. University of Wisconsin Small Business Development Center.

Vosikis, G. (1980). A strategic disadvantage profile of the stages of development of small business: The experience of retail and service small business in Georgia. (Doctoral dissertation, University of Georgia, 1979). Dissertation Abstracts International, 40, 5931A Wichmann, H. (1983). Accounting and marketing - key small business problems. American Journal of Small Business, 4(7), 19-26. 


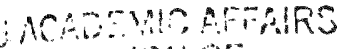

olvision

GADUATE STUPIES

FLORIDA INTERNATIONAL UNIVERSITY GRADUATE PROGRAM

\section{RESULTS OF THE THESIS/DISSERTATIONDEFENSE}

The purpose of this document is to announce the outcome of the thesis/dissertation defense.

Date: $11-22-91$

Name

Granville, Dickson

Last
First

20128 S.W. 123 Drive

Middle

Address

Street

\begin{tabular}{rrr} 
Miami & FL & 33177 \\
\hline City & State & Zip
\end{tabular}

Doctoral Program

SS\# $121-60-7648$

Bus. Phone

Home Phone 232-0860

The undersigned certify that the final oral defense of the thesis/dissertation of the above named student has been

Title of thesis/dissertation A study of the Characteristics of Successful Sma11

Committee:

Adult Education successful $X$ unsuccessful

Black-Owned Enterprises in Dade County, Florida

Douglas H. Smith, Ph.D. DHe

Major Professor

Carlos M. Alvarez, Ph.D

Member $\frac{\text { Robert S. Winter, Ph.D. }}{\text { Member }}$

\section{Ru'}

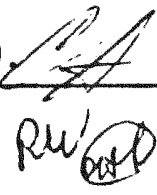

Code

0177 